\title{
Diverse Risk/Cost Balancing Strategies for Flexible Tool Management in a Supply Network
}

\author{
Roberto Teti, D. D'Addona \\ Department of Materials and Production Engineering \\ University of Naples Federico II, Piazzale Tecchio, Naples, 80125, Italy
}

\begin{abstract}
:
This work is a part of a wider scope research concerned with the development and implementation of a MultiAgent Tool Management System (MATMS) for automatic tool procurement. The design, functioning, and performance of diverse Flexible Tool Management Strategies (FTMS) integrated in the MATMS is illustrated here. The MATMS operates in the frame of a negotiation based multiple-supplier network where a turbine blade producer (customer) requires from external tool manufacturers (suppliers) the performance of dressing operations on worn-out CBN grinding wheels for nickel base alloy turbine blade fabrication. The diverse FTMS paradigms, configured as domain specific problem solving functions operating within the MATMS intelligent agent holding the responsibility for optimum tool inventory sizing and control, have been tested by tool inventory management simulations and comparison with real industrial cases.
\end{abstract}

Keywords: Tool Management, Inventory Control, Multi-Agent Systems, Supply Networks.

\section{ACKNOWLEDGEMENTS}

This work was carried out within the SICSI Postgraduate Program, Cycle V, Technological Curriculum, Class A033, acad. year 2005/2006, University of Naples Federico II.

The working group members $\mathrm{V}$. Ammendola, $\mathrm{L}$. Chiapparelli, M. Giovine, M. Letizia, M. Lorenzello, C. Martullo, D. Panico, G. Pastore, and V. Postiglione are gratefully acknowledged for their effort and collaboration.

The paper draws on the thesis work of A. Bontempi and S. Marinelli whose contributions are acknowledged.

\section{INTRODUCTION}

In recent times, a novel software architecture to manage supply networks at the tactical and operational levels has emerged. The supply network is viewed as a system made of a set of intelligent (software) agents, each responsible for one or more activities in the supply network and each interacting with other agents in planning and executing their responsibilities [1]. The adoption of agent-based or multi-agent technology is founded on the three main system domain characteristics [2]: data, control, expertise or resources are inherently distributed; the system is naturally regarded as a society of autonomous cooperating components; the system contains legacy components that must interact with other, possibly new software components.

Supply network management by its very nature has all the above domain characteristics [3]. A supply network consists of suppliers, factories, warehouses, etc., working together to fabricate products and deliver them to customers. Parties involved in the supply network have their own resources, capabilities, tasks, and objectives. They cooperate with each other autonomously to serve common goals but also have their own interests. A supply network is dynamic and involves the constant flows of information and materials across multiple functional areas both within and between network members.

Multi-agent technology therefore appears to be particularly suitable to support collaboration in supply network management.

This research work is concerned with the development and implementation of a Multi-Agent Tool Management System (MATMS) for automatic tool procurement [4].
The MATMS operates in the frame of a negotiation based multiple-supplier network where a turbine blade producer (customer) requires from external tool manufacturers (suppliers) the performance of dressing operations on worn-out CBN grinding wheels for nickel base alloy turbine blade fabrication $[5,6]$.

In this paper, the design, functioning and performance of diverse Flexible Tool Management Strategies (FTMS) integrated in the MATMS is illustrated. Each FTMS paradigm is configured as a domain specific problem solving function operating within the intelligent agent of the MATMS, Resource Agent, holding the responsibility for optimum tool inventory sizing and control.

\section{MULTI-AGENT TOOL MANAGEMENT SYSTEM}

The production of an aircraft engine model involves the machining of turbine blades through a pre-determined set of $C B N$ grinding wheel part-numbers $(P / N)$. Each $P / N$ can machine a maximum number of turbine blades (pieces) during its planned life cycle.

Then, it is shipped to an external tool supplier to be dressed and remains out of stock for a time period defined as dressing cycle time.

For each $\mathrm{P} / \mathrm{N}$, a sufficient number of $\mathrm{CBN}$ grinding wheel serial-numbers $(\mathrm{S} / \mathrm{N})$ must be in stock at all times (on-hand inventory) to prevent tool run-out and production interruptions.

The $\mathrm{P} / \mathrm{N}$ on-hand inventory size, $\mathrm{I}$, is controlled by: \# of pieces/month, P; \# of pieces/wheel, G; \# of months required without new or dressed wheel supply, $C$ (coverage period), heuristically selected.

The wheel demand, $D$, for each $P / N$ is given by:

$$
D=(P / G) * C-I_{0}
$$

where: $P / G=$ tool demand rate (\# of wheels/month); $I_{0}=$ initial $\mathrm{P} / \mathrm{N}$ inventory size.

In traditional tool management, the CBN grinding wheel $\mathrm{P} / \mathrm{N}$ inventory size is strategically planned by selecting, on a heuristic basis, an appropriate coverage on-hand inventory (\# of $\mathrm{S} / \mathrm{N}$ for production needs in the coverage period C). This procedure does not always prove adequate: in some cases, the expected inventory level trend matches the required one; in other cases, it is underestimated, with risk of stock-out, or overestimated, 
with excessive capital investment [5]. Accordingly, the P/N inventory level is increased or reduced on the basis of skilled logistics staff knowledge, resulting in historical inventory size trends: these are fit solutions that prevent tool run-out and useless investment and can be used as a reference for assessing alternative tool management strategies, independent from expert staff performance.

The MATMS activities are performed according to the multi-agent interaction and cooperation protocols illustrated in Figure $1[4,6]$. The figure reports the block scheme of the developed MATMS divided into three functional levels:

- the Supplier Network Level, including the external tool manufacturers in the supply network;

- the Enterprise Level, including the logistics of the turbine blade producer company;

- the Plant Level, including the production lines of the turbine blade producer company.

The Supplier Network Level is responsible for carrying out the dressing jobs on worn-out CBN grinding wheels. It comprises only one type of agents, the Supplier Order Acquisition Agents $\left(S O A A_{i}\right)$, representing the external tool manufacturers (suppliers) activity of acquiring dressing job orders from the turbine blade producer (customer). The $S O A A_{i}$ negotiate dressing job orders with the enterprise Order Distribution Agent (ODA) and exchange wornout/dressed CBN grinding wheels with the enterprise Warehouse Timer Agent (WTA).

The Enterprise Level is responsible for coordinating the MATMS activities to achieve the best possible results in terms of its goals, including on-time delivery, cost minimization, and so forth. It comprises different intelligent agents performing the fundamental tool management activities.

- The Resource Agent (RA) that merges the functions of tool inventory management, tool resource demand estimation and determination of tool order quantities; the RA domain specific problem solving function is the FTMS paradigm, dealt with in detail in section 3 . Initially, the RA receives information on $\mathrm{CBN}$ grinding wheel end-of-life events from the Production Agents $\left(\mathrm{PA}_{\mathrm{j}}\right)$. For each $\mathrm{CBN}$ grinding wheel part-number, the RA requests a supplierindependent dressing cycle time prediction to the Dressing Time Prediction Agent (DTPA) [5]. Using this input and the information on production plans running at the Plant Level, it estimates the demand for CBN grinding wheel dressings. If it deems necessary to issue a dressing job order for a given $\mathrm{CBN}$ grinding wheel partnumber, it requests the ODA to select an external tool manufacturer in the supply network for dressing job order allocation.

- The Order Distribution Agent (ODA) that selects the external supplier to which the CBN grinding wheel dressing job order should be allocated on the basis of negotiations and constraints. The ODA domain specific problem solving function for order allocation is implemented under ILOG OPL Studio $3.5[4,6,7]$.

- The Dressing Time Prediction Agent (DTPA) that carries out the predictions of $\mathrm{CBN}$ grinding wheel dressing cycle times, founded on historical data, under both a supplierindependent [5] and a supplier-dependent basis [6]. The DTPA domain specific problem solving function is a neuro-fuzzy paradigm known as Adaptive Neuro-Fuzzy Inference System (ANFIS) [8 - 11].

- The Knowledge \& Data Base Agent (K\&DBA) that handles all the information relevant for tool management activities, including the updating of historical data on CBN grinding wheel dressing cycles.
- The Warehouse Timer Agent (WTA) that takes care of incoming and outgoing CBN grinding wheels, including the evaluation of actual dressing cycle times.

The Plant Level is responsible for the manufacturing of turbine blades. It comprises only one type of agents, the Production Agents $\left(\mathrm{PA}_{\mathrm{i}}\right)$, representing the various production lines of the turbine blade producer factory. When a tool end-of-life event occurs, the relevant $P A_{i}$ sends the worn-out CBN grinding wheel to the WTA and the corresponding information (part-number and serialnumber) to the RA to initiate the FTMS procedure. After dressing job completion, the external suppliers send the dressed CBN grinding wheels to the WTA that forwards them to the appropriate PA.

\section{FLEXIBLE TOOL MANAGEMENT STRATEGIES}

The development and implementation of diverse Flexible Tool Management Strategies (FTMS) is presented as an alternative to the traditional tool management procedure. Each FTMS is integrated in a Multi-Agent Tool Management System (MATMS) for automatic tool procurement, designed to operate in the frame of a negotiation-based multiple-supplier network. The task of the FTMS is the optimal tool inventory sizing and control, including tool supply cost and stock-out risk minimization.

The main responsibility of the RA in the MATMS is the optimum tool inventory sizing and control of CBN grinding wheels for turbine blade fabrication, with reference to the minimisation of tool management cost and stock-out risk. This task is carried out by the RA through its domain specific problem solving function, the FTMS paradigm.

Each time a worn-out CBN grinding wheel leaves a production line, a new part-number demand is set up as a function of the dressing cycle time. If an accurate estimate of the dressing cycle time of each worn-out CBN grinding wheel is provided by the DTPA, the demand for that partnumber can be compared with the part-number on-hand inventory. Moreover, as a CBN grinding wheel purchase order issued at a certain time requires a suitable lead time ( $\left.T_{\text {pur }}\right)$ before an actual delivery takes place, to avoid stockout it is necessary to have available at any time a minimum stock at least equal to the part-number demand during the purchase order lead time $T_{\text {pur }}$.

A FTMS was initially presented in [5] whose rationale was to make sure that the part-number on-hand inventory size, I, remains within an interval defined by two real-time control limits: the part-number demand during $T_{\text {pur }}$ (lower limit, $I_{\min }$ ) and the part-number demand calculated using the dressing cycle time predicted by the DTPA (upper limit, $\left.I_{\max }\right)$. The inventory level, I, is left free to fluctuate within the limits $\left[I_{\min }, I_{\max }\right]$, provided neither of them is crossed, and whenever I decreases due to a tool wear-out event, the CBN grinding wheels are sent out for dressing. Otherwise, the turbine blade producer logistics must either provide additional serial-numbers when the lower control limit is crossed $\left(I<I_{\min }\right)$ or reduce the part-number on-hand inventory by suspending the dressing job order allocation when the upper control limit is crossed $\left(I>I_{\max }\right)$ to bring back the stock level within the control range.

This FTMS paradigm was called Planned Demand Rate (PDR) approach as the $P / N$ demand rate $P / G$ is kept constant during the tool management period. The control range lower limit is constant and given by $I_{\min }=P / G * T_{\text {pur }}$, where $T_{\text {pur }}$ is a constant as its historical records are only slightly variable. The control range upper limit, $I_{\max }$, varies each time a tool wear-out event occurs as a function of the dressing time predictions, $\mathrm{T}(\mathrm{j}+1)$, provided by the DTPA: $I_{\max }(j)=P / G *\left[T(j+1)+T_{\text {int }}\right]$ where $j$ is the counter of wornout wheels and $T_{\text {int }}$ is the time to transfer the tool to its production line. 


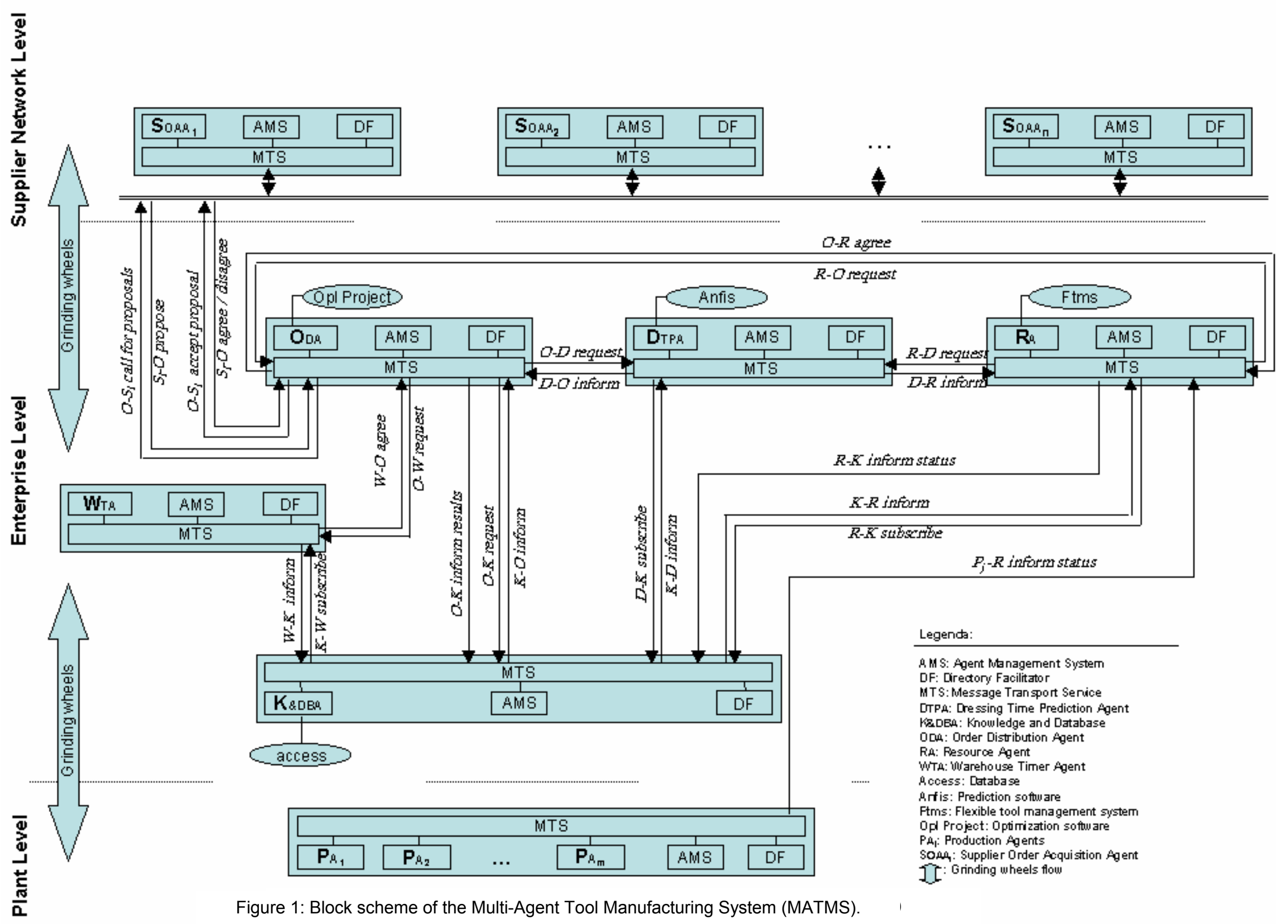




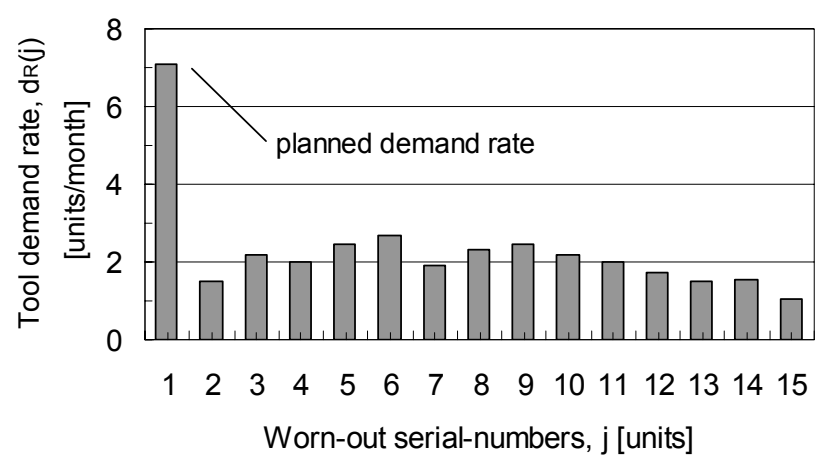

(a)

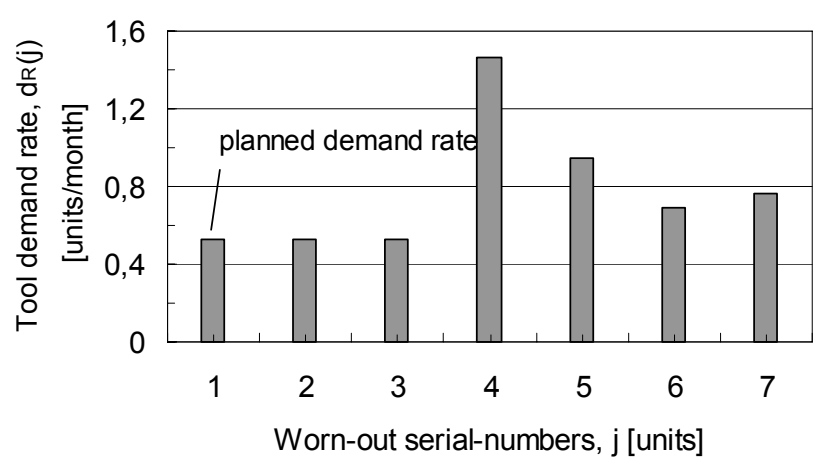

(b)

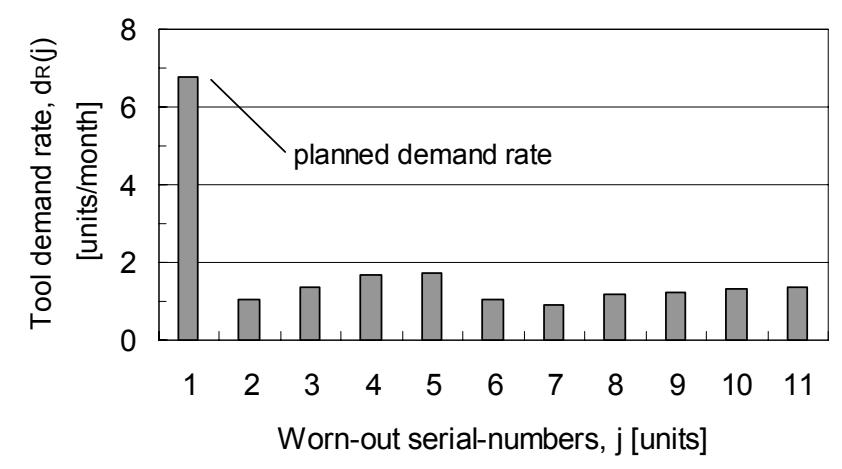

(c)

Figure 2: Adaptive tool demand rate, $d_{R}(j)$, vs. wornout serial-numbers, $\mathrm{j}$, in a period of one year, for $\mathrm{P} / \mathrm{Ns}$ :

(a) M8110855, (b) M8117351, (c) M8137161.

\subsection{Current Inventory Level Decision Marking (INVADAPT)}

The planned tool demand rate $P / G$ is the ratio of two constant parameters, representing the average tool demand in the reference period. Thus, this parameter is unable to take into account any deviation from currently established production plans and/or current estimates of mean tool life. In fact, actual tool demand rates can be higher than the planned ones due to higher production volumes or unexpectedly shorter tool lives. They can also become lower than the planned ones because of lower production volumes. As a consequence, actual tool demand rates occurring in reality can notably differ from the planned tool demand rates and cause serious difficulties to the tool management activity.

To solve this problem, the concept of adaptive tool demand rate, $d_{R}(j)$, is introduced and defined as [5]:

$d_{R}(j)= \begin{cases}P / G, & \text { if } t(j) \leq 1 \\ j / t(j), & \text { otherwise }\end{cases}$

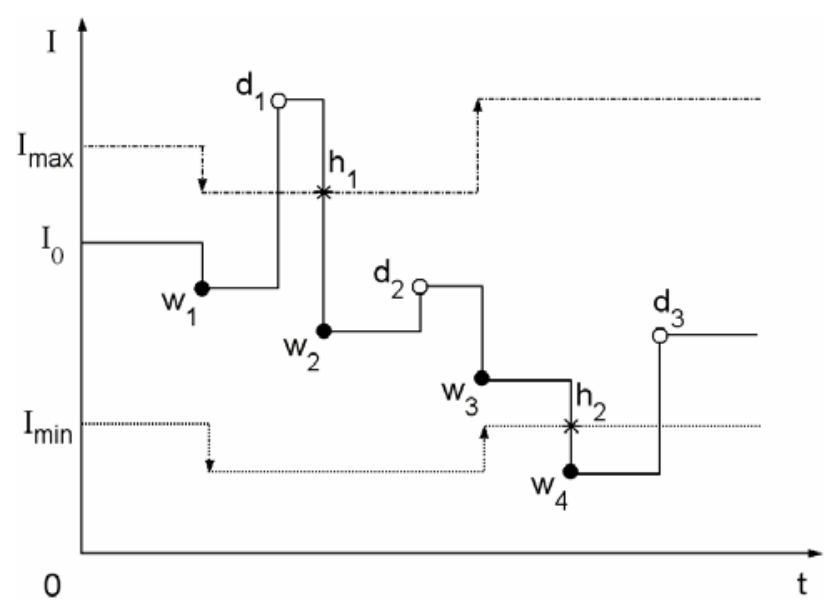

Figure 3: Generic part-number

on-hand inventory level, I, vs. time, t.

$w=$ tool wear-out event $(\bullet) ; d=$ tool delivery event $(0)$; $\mathrm{h}=$ control limit crossing due to a w-event $\left({ }^{*}\right)$.

where: $t(j)$ is the time (in months), computed from the start of the FTMS procedure, at which the dressing operation for worn-out serial-number is proposed. From eq. 2, it can be noted that the planned tool demand rate $P / G$ is taken as initial value for the adaptive tool demand rate $d_{R}(j)$. This value is kept constant during the first month of flexible tool management. In Figure 2, the adaptive tool demand rate for the $3 \mathrm{CBN}$ grinding wheel part-numbers (M8110855, M8117351, M8137161) is reported vs. wornout serial-numbers $\mathrm{j}$ for a time period of one year. In the Adaptive Demand Rate (ADR) approach, the control limits are given by [5]:

$$
\left\{\begin{array}{l}
I_{\text {min }}(j)=d_{R}(j) * T_{\text {pur }} \\
I_{\text {max }}(j)=d_{R}(j) *\left[\mathcal{T}(j+1)+T_{\text {int }}\right]
\end{array}\right.
$$

where: $\mathrm{j}=$ counter of worn-out $\mathrm{S} / \mathrm{Ns}, T(\mathrm{j}+1)=\mathrm{DTPA}$ dressing time prediction, $T_{\text {int }}=$ internal time, i.e. time for a new or dressed grinding wheel to be transferred to the production line (constant for a given manufacturing plant). In Figure 3 , the on-hand inventory control of a generic CBN grinding wheel $P / N$ is described to illustrate the FTMS functioning for the INVADAPT approach.

According to eq. 3 , as $T_{\text {int }}$ is a constant typical of the manufacturing plant, $T_{\text {pur }}$ is constant on a historical basis, and $P / G$ is updated yearly by the turbine blade producer for each one year period, the upper control limit I max varies or stays constant as a function of the current adaptive demand rate $d_{R}(j)$ and the predicted dressing cycle time $\mathcal{T}(j+1)$, whereas the lower control limit $I_{\min }$ varies or stays constant only as a function of the current value of $d_{R}(j)$.

At time $t=0$, the $P / N$ on-hand inventory size is $I_{0}$. Each time CBN grinding wheels wear-out (w-events in Figure 3 ), the P/N on-hand inventory level, I, decreases, the adaptive demand rate values are updated, and supplierindependent dressing cycle time predictions, $T(j+1)$, are issued by the DTPA. Each time new or dressed CBN grinding wheels are delivered by the suppliers, the $P / N$ on-hand inventory size, I, grows but the control limits $I_{\text {min }}$ and $I_{\max }$ are not affected. However, if I crosses the upper control limit $\left(I>I_{\max }\right.$ at $d_{1}$ in Figure 3$)$, at the next w-event $\left(w_{2}\right.$ in Figure 3) $I-I_{\max }$ worn-out $S / N$ s are kept on-hold in the enterprise warehouse $\left(h_{1}\right.$ upper control limit crossing, Figure 3). After control limits updating, if $I$ is within the control range the worn-out tools must be sent out for dressing but no tool purchase is required $\left(w_{1}, w_{3}\right.$ in Figure $3)$. If I crosses the lower control limit $\left(I<I_{\min }\right.$ at $w_{4}$ in Figure 3), the worn-out tools must be sent out for dressing and further $\left(I_{\min }-I\right) S / N s$ must be provided. If worn-out 
S/Ns are on-hold, they are sent out for dressing in partial or total substitution for new tool purchases $\left(h_{2}\right.$ lower control limit crossing, Figure 3 ). At any rate, the number of required $\mathrm{CBN}$ grinding wheels exceeding the available on-hold worn-out S/Ns must be newly purchased.

\subsection{Fixed Horizon Inventory Level Decision Marking (I-FUTURE)}

The above version of the FTMS has the drawback of a "shortsighted" approach because decisions are taken only on the basis of the current inventory level, I(t), with no consideration for what will happen in the future. To overcome this problem, a "non shortsighted" version of the FTMS procedure, called I-FUTURE, is proposed whereby the FTMS takes into account for tool management decision making the value of a future onhand inventory level, $\mathrm{I}_{\text {fut }}\left(\mathrm{t}+\mathrm{T}_{\mathrm{rt}}\right)$, instead of the current onhand inventory level, $I(t) . I_{\text {fut }}$ is the on-hand inventory level calculated with reference to a future time $\left(t+T_{r t}\right)$ and is:

$\mathrm{I}_{\text {fut }}\left(t+T_{\text {rt }}\right)=I(t)+X+Y+Z-d_{R}(w) * T_{r t}$

where:

$-\mathrm{T}_{\mathrm{rt}}=$ reaction time of the FTMS;

- $X=$ number of worn-out tools sent out for dressing before the start of the FTMS procedure $(\mathrm{t}<0)$ and expected to be available at time $\left(\mathrm{t}+\mathrm{T}_{\mathrm{rt}}\right)$;

- $Y=$ number of worn-out tools sent out for dressing during the FTMS procedure $(\mathrm{t}>0)$ and predicted be available at time $\left(\mathrm{t}+\mathrm{T}_{\mathrm{rt}}\right)$;

- $Z$ = number of newly purchased worn-out tools not yet delivered: these will be positively available at time $(t+$ $T_{r t}$ ) because purchase time $T_{\text {pur }} \leq T_{r t}$.

- $d_{R}(w){ }^{*} T_{r t}=$ number of worn-out tools that will wear-out during reaction time $T_{r t}$ under constant $d_{R}$ conditions.

In the first "non shortsighted" approach I-FUTURE, if $\mathrm{I}(\mathrm{t}) \geq$ $I_{\min }, T_{r t}$ is the sum of the mean historical dressing cycle times $d_{c t}\left(6\right.$ weeks) and the internal time $T_{\text {int }}(5$ weeks):

$\mathrm{T}_{\mathrm{rt}}=\mathrm{d}_{\mathrm{ct}}+\mathrm{T}_{\mathrm{int}}=6$ weeks +5 weeks $=11$ weeks

If $\mathrm{I}(\mathrm{t})<\mathrm{I}_{\min }, \mathrm{T}_{\mathrm{rt}}$ is considered equal to the purchase time $\mathrm{T}_{\text {pur }}(9$ weeks):

$\mathrm{T}_{\mathrm{rt}}=\mathrm{T}_{\text {pur }}=9$ weeks

\subsection{Variable Horizon Inventory Level Decision Making (INVADAPT_NS)}

INVADAPT_NS is the second version of the "nonshortsighted" FTMS approach.

In INVADAPT_NS, the FTMS reaction time $T_{r t}$ is not considered equal to a constant value ( 9 or 11 weeks), like in I-FUTURE, but is given by the dressing cycle time prediction $\tau(j+1)$ provided by the DTPA plus the value of the internal time $T_{\text {int }}$ :

$\mathrm{T}_{\mathrm{rt}}=T(\mathrm{j}+1)+\mathrm{T}_{\mathrm{int}}$

\section{TOOL INVENTORY MANAGEMENT SIMULATIONS}

To carry out tool inventory management simulations through the FTMS paradigms, two files ".dat" must be created starting from the Excel sheets received from the turbine blade producer (Figure 4). The original files are made of 6 sheets; for data file preparation, only sheets 1 and 2 are used. The information contained in sheet 1 are:

- DISASSEMBLY: date at which the worn out CBN grinding wheel is disassembled.

- ASSEMBLY: date at which the dressed CBN grinding wheel is assembled for service.

- CAUSE: if the grinding wheel has been purchased (C/Construction), if it is worn out $(\mathrm{C} / \mathrm{Job})$, if it has been sent for dressing but the dressing has been considered unnecessary (C/Check).

- DEPARTURE: dressing start date (it does not coincide with the DISASSEMBLY date since the worn out CBN grinding wheels are sent to the suppliers in groups).

- SUPPLY: date at which the dressing is completed; it coincides with the date of arrival.

To these initial information, two other items are added in two additional columns:

- SERIAL NUMBER: progressive number that identifies the single worn out CBN grinding wheel.

- DRESSING TIME: time, in weeks, necessary for dressing [(ARRIVAL - DEPARTURE) / 7], only for C/Job and $\mathrm{C} /$ Check causes.

The file obtained is shown as an example in Figure 5 . For instance, in row 3 of Figure 5 " 1 " was added in column $F$ to indicate the first grinding wheel in the simulation; and "10" was added in column G, equal to (E3 - D3) / 7, that must be rounded down or up to the nearest integer.

Using these data, the first file ".dat" can be created with the Block Notes. The name of this file is constituted by the $\mathrm{P} / \mathrm{N}$ followed by the word "pastimes" and the extension ".dat" (this syntax must be followed rigidly otherwise the software cannot read the file). In the example, the file name is "U5102Npastimes.dat". The creation of the file starts by inserting in the Block Notes file a first column containing the last ten dates of assembly of the year ' 99 taken from column B of Figure 5 (in the example, from row 3 to row 12). If the number of dates of assembly for the ' 99 is less than ten, it is enough to take all the available ones. To this first column, a second column is added with the corresponding dressing times (column G) ${ }^{1}$. The obtained file is reported in Figure 6. If there are no dates of assembly for the year '99, the dates that precede the year of simulation are used (to be verified).

The name of the second file ".dat" is: $\mathrm{P} / \mathrm{N}$ followed by the acronym "Ih" (Inventory historical) and the extension ".dat". In the example, the name is "U5102NIh.dat". The information for the creation of this file are available in Excel file sheet 2 in Figure 7 . In the page of the Block Notes file, a first column containing the dates of the events beginning from the 1st of January 2000 (column A, Figure 7) and a second column containing the corresponding availabilities (column D, Figure 7) are pasted. The obtained file is reported in Figure 8.

For some files, it can happen that for the date of 1 st of January there are several rows (rows 50 and 51 of Figure 9 ). In this case, reference is made to column $B$, where it can be seen that B50 is empty while B51 contains "1"2. This means that on the 1st of January an event has occurred and the corresponding row to such event is now 51 . So, in the file "Ih.dat" the date of the 1st of January is copied only once and the corresponding availability must be read in row 51. In the example of Figure 9, the availability at the 1st of January is therefore 14 and not 13. In Figure 10, the file "U8102lh.dat" is reported. The built ".dat" files must be inputted in the Work directory of MatLab. The two ".dat" files have been built using a historical data base so to allow the FTMS to make reliable forecasts of the dressing times and to calculate the tool demand rate. These data, in fact, allow the software to decide whether a worn out CBN grinding wheel should be sent to dressing or not.

\footnotetext{
1 To build this file, the proper information are copied from columns $B$ and $G$ and pasted on an Excel work sheet in 2 nearby columns and then from the work sheet to the Block Notes file.

2 If column B contains "1" or "-1," an event has happened.
} 
[ile Modifica visualizza Innserisci Formato ștrumenti Dati Finestra ?

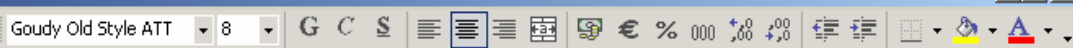

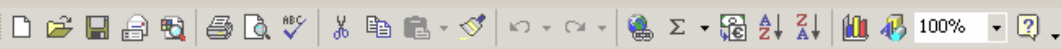

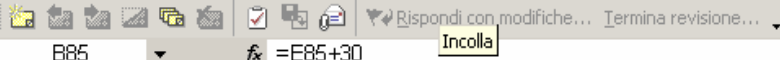

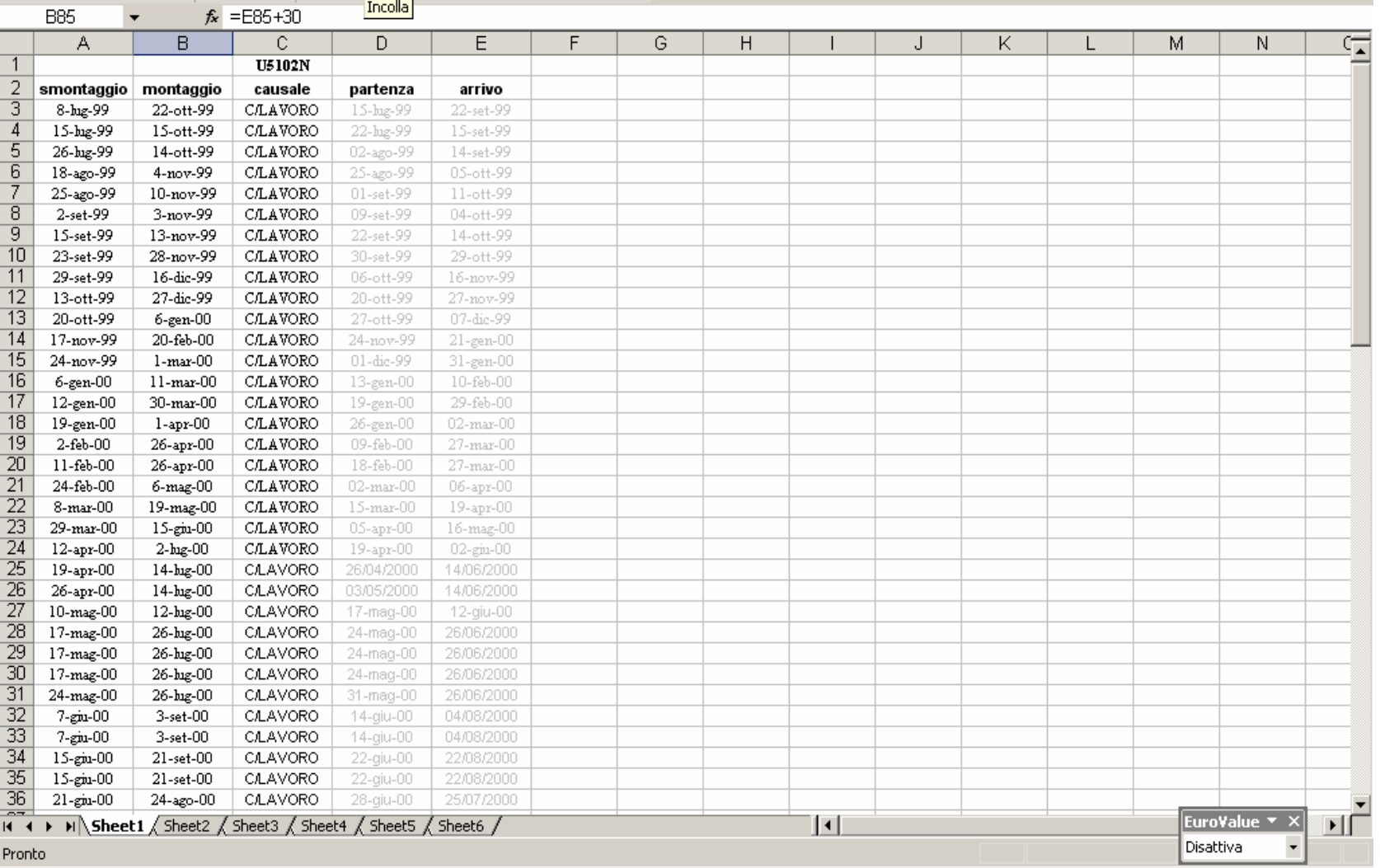

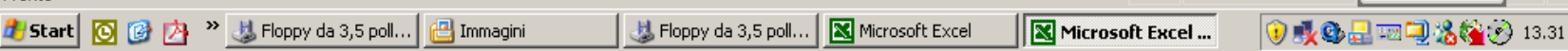

Figure 4: Excel file (sheet 1) received by the turbine blade producer (P/N U5102N).

\section{Microsoft Excel - U5102N}

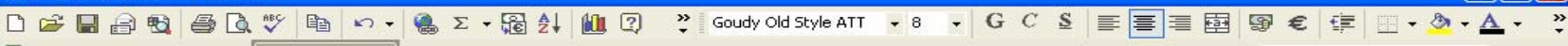
图 Eile Modifica visualizza EuroValue $>x$ to ștrumenti Dati Finestra ?

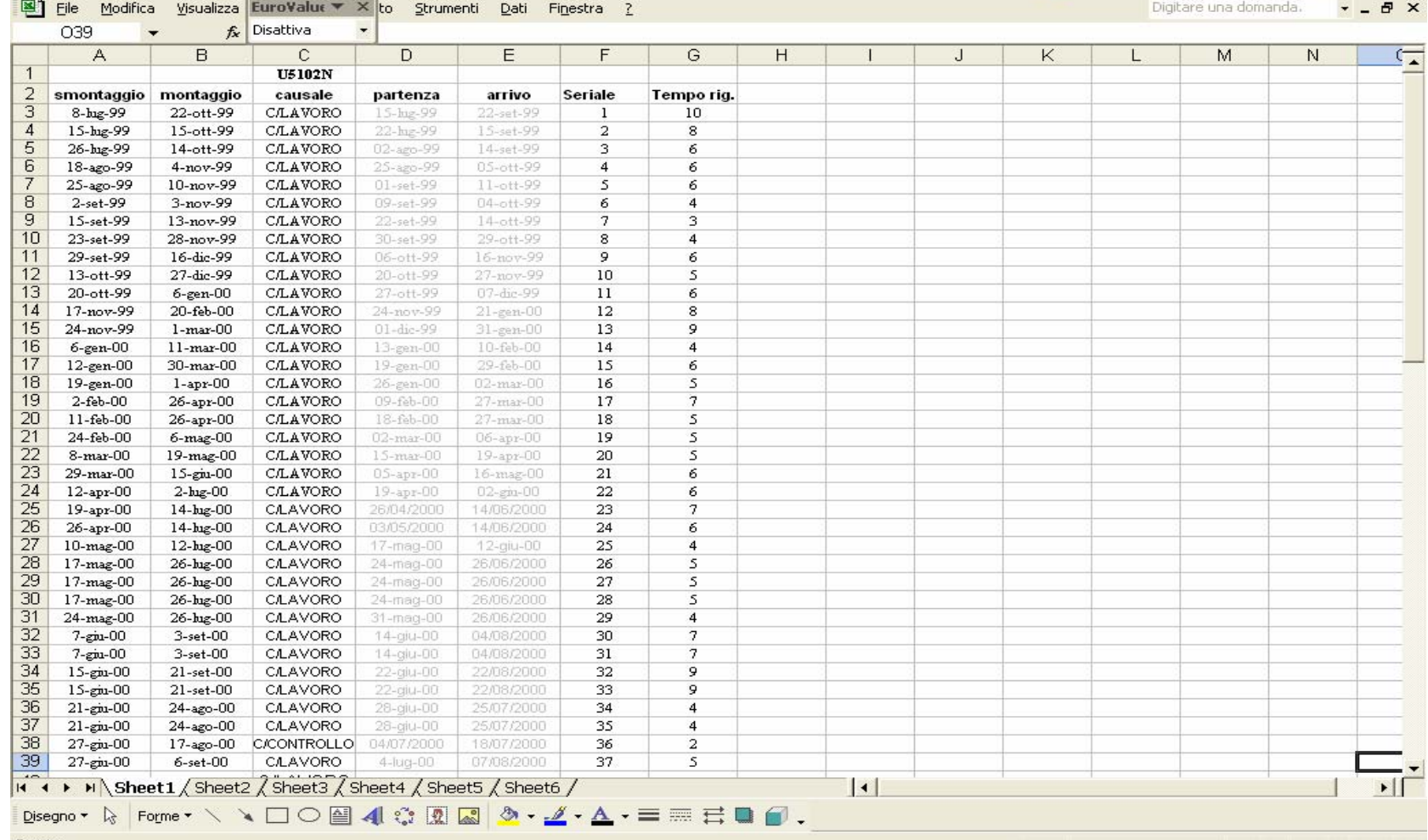

Figure 5: Obtained Excel file sheet 1 after the addition of Serial Number and Dressing Time (P/N U5102N). 


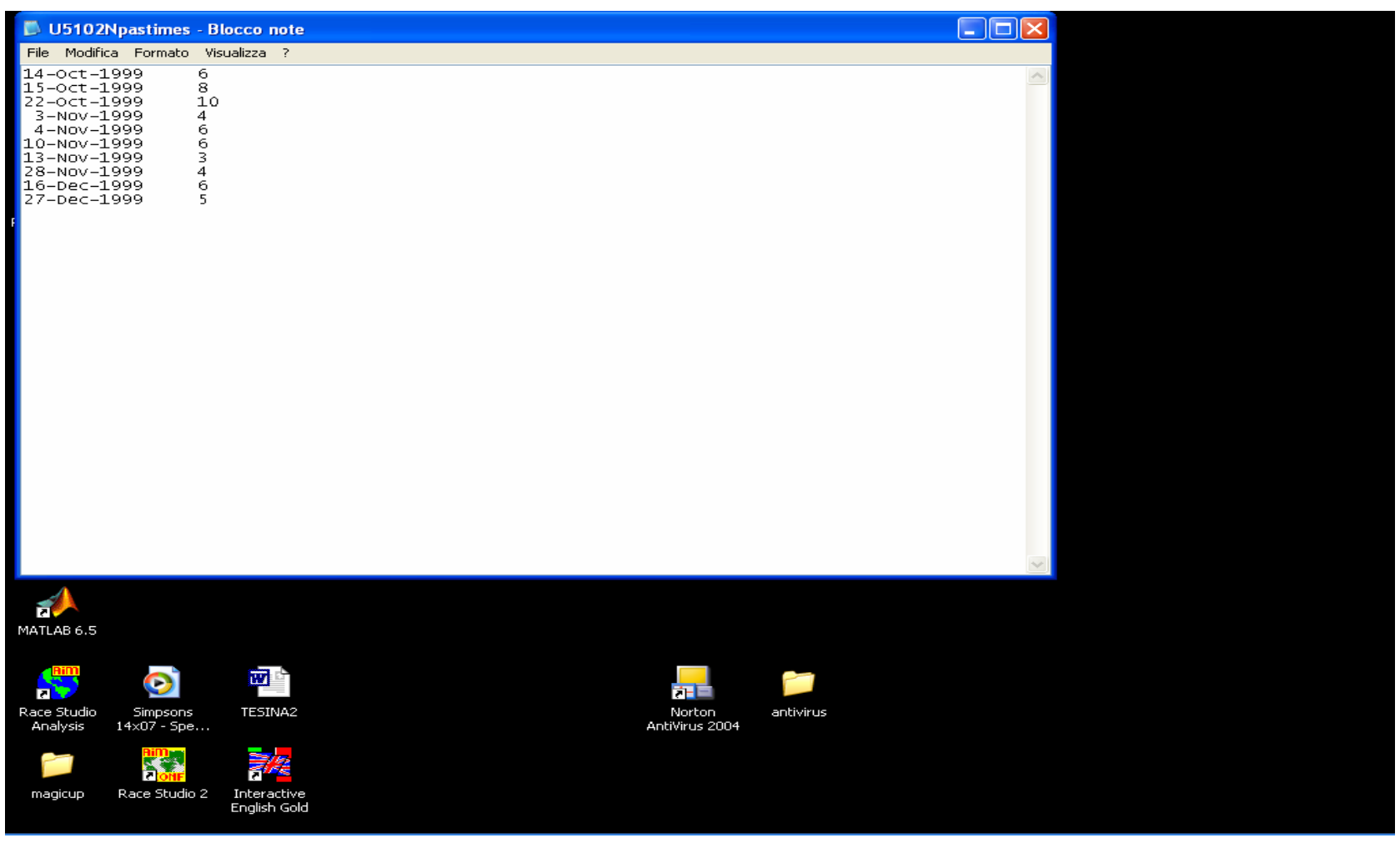

Figure 6: Block Notes file for P/N U5102N pastimes data (first “.dat” file).

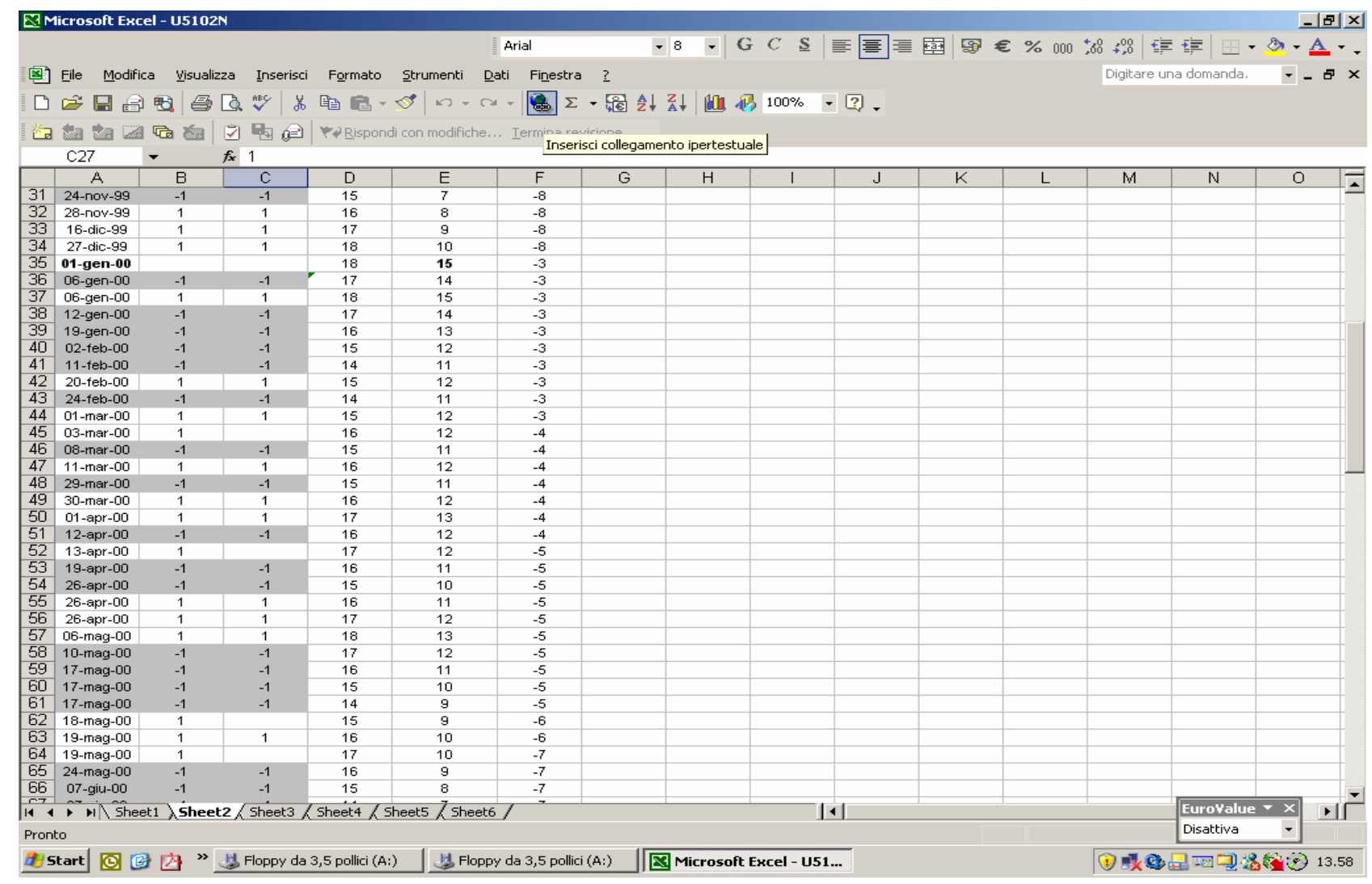

Figure 7: Excel file sheet 2 for P/N U5102N.

Column A: Event Date, B: Real Trend, C: Ideal Trend, D: Availability, E: rig. x m.c., F: Demand Calculation. 


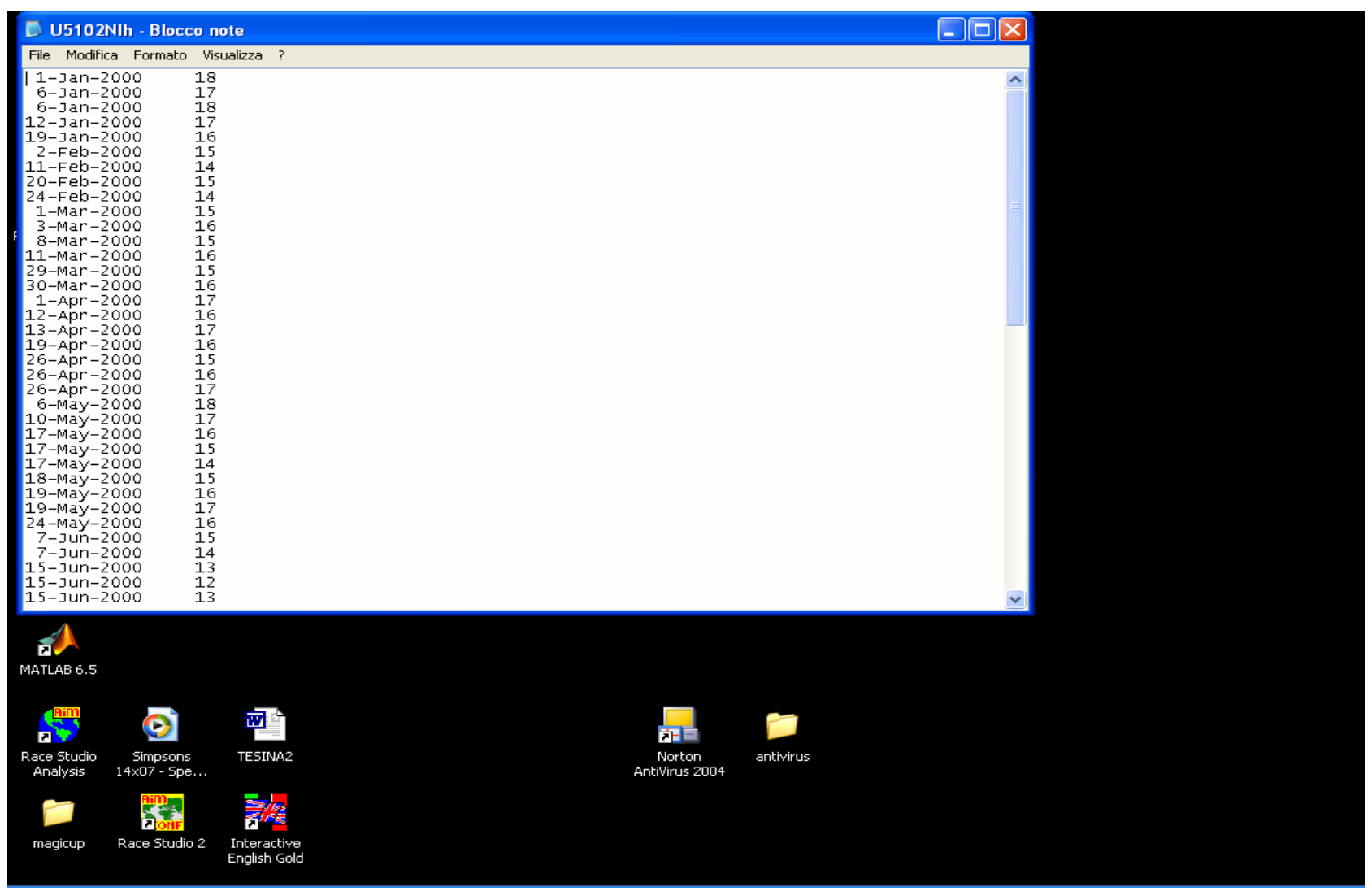

Figure 8: Block Notes file for P/N U5102NIh date (second “.dat” file).

\section{Microsoft Excel - U8102}

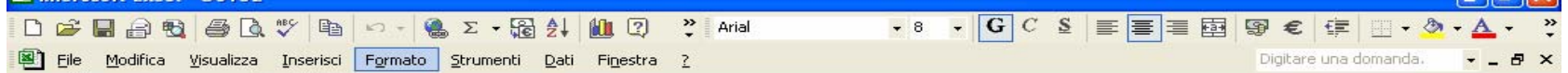

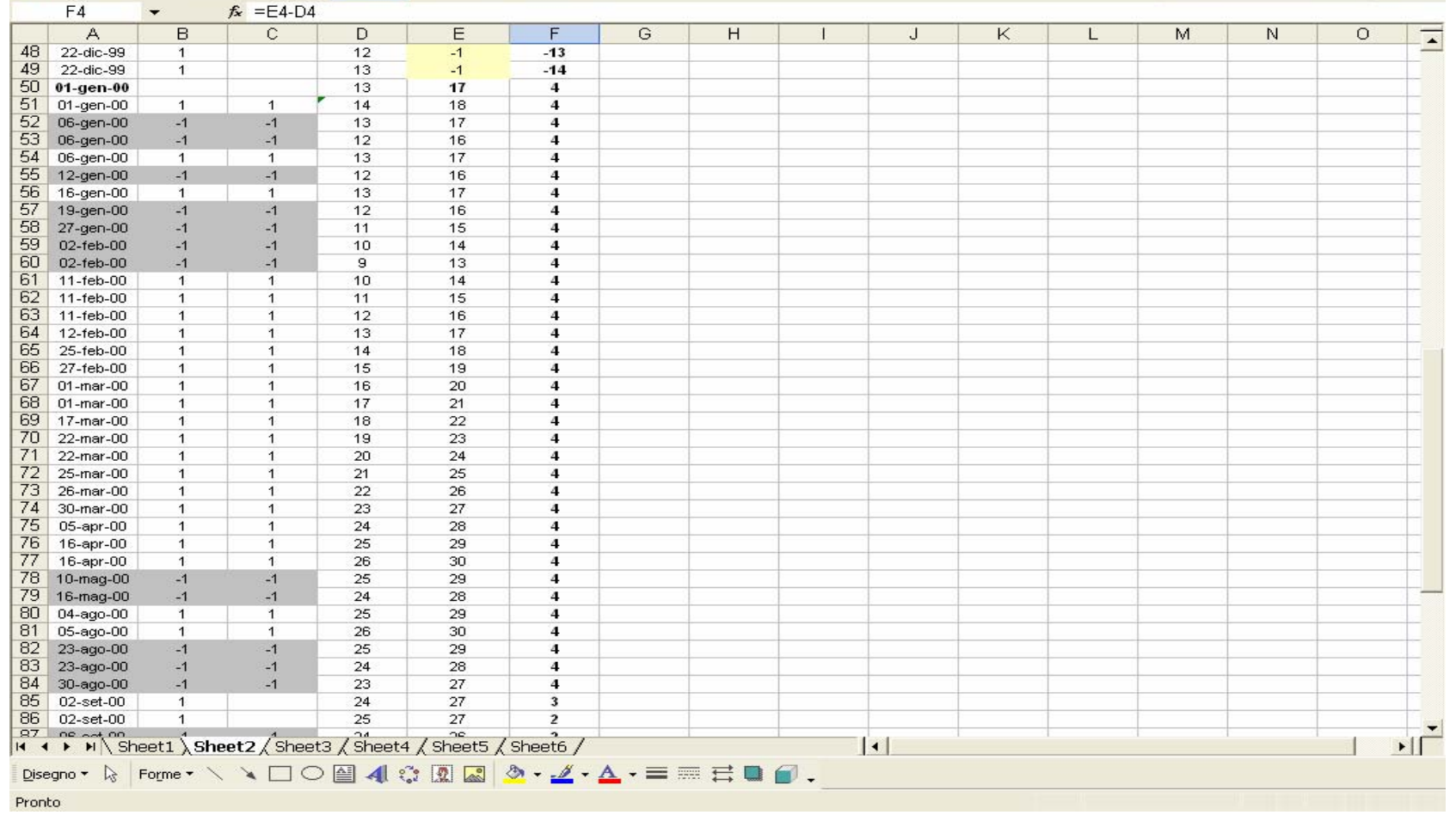

Figure 9: Excel file sheet 2 for P/N U8102. 


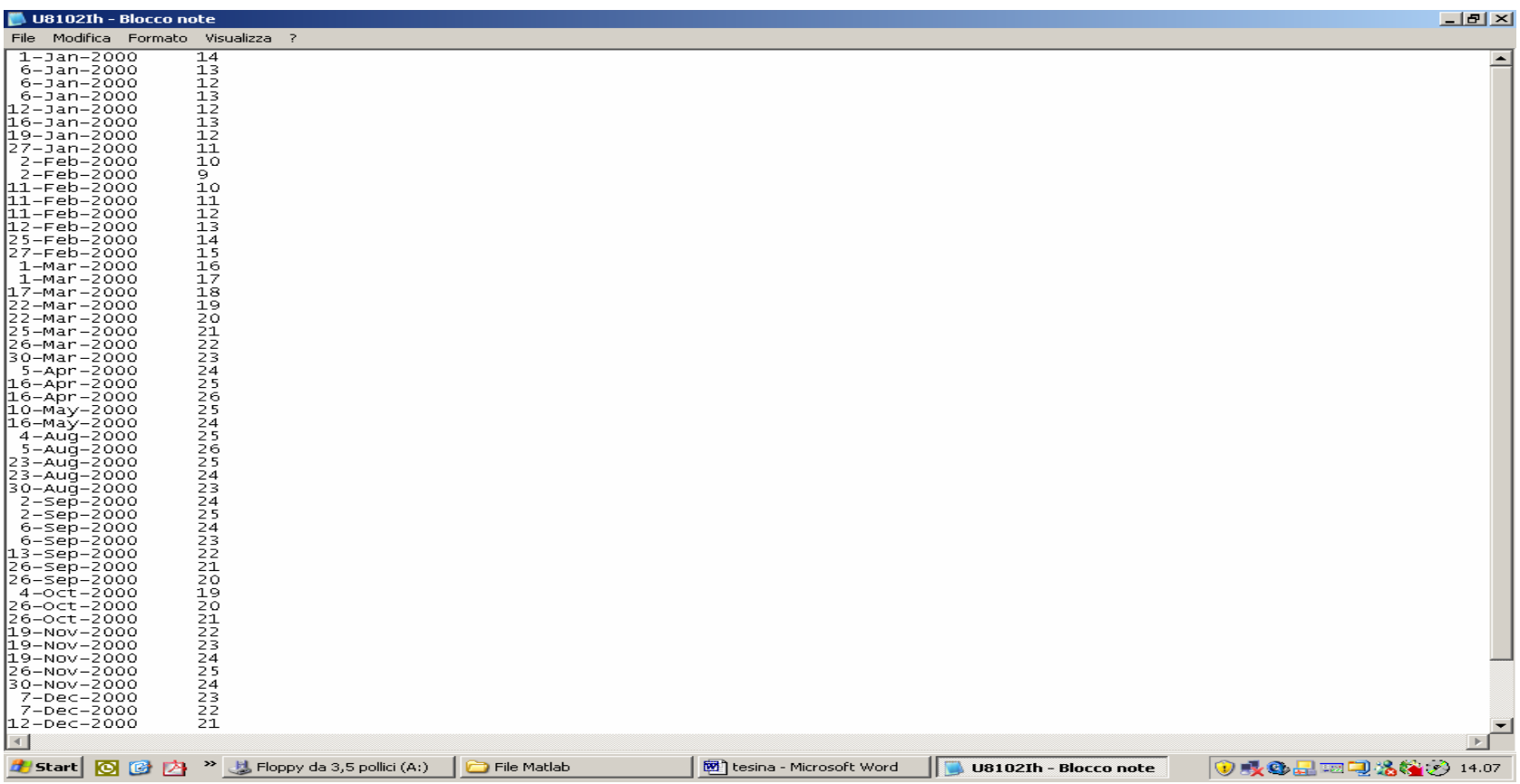

Figure 10: Block Notes file for P/N U8102lh data.

In order to carry out a simulation, an Excel file must be created. This file is built starting from the available data in the file of Figure 5 (that is the original Excel file to which the column of the serial number and the column of the dressing time have been added). This is an Excel sheet from which we (and not MatLab) will read the information to input into the simulation; it is made up of five columns (Figure 11):

- DATE: in the first column, the dates of disassembly and assembly events related to the year 2000 taken from column A (starting from row 16) and from column B (starting from row 13) of Figure 5 are listed together in chronological order

- TYPE: in the second column, the type of event is indicated:

- $s$ (for shipment) for a disassembly date

- d (for delivery) for an assembly date

- NUMBER: it counts the number of events for each date (in this file, in each row, only one event is listed)

- SERIAL NUMBER: this is retrieved from column $F$ of Figure 5

- DRESSING TIME: this is retrieved from column $G$ of Figure 5.

The procedure for building the above file is the following:

- copy the dates of disassembly from column A of Figure 5 and paste it in the first column of a temporary Excel sheet, insert in the second column the letter "s", insert in the third column the number "1" and in the fourth column the corresponding serial numbers (they must be retrieved from column $\mathrm{F}$ of Figure 5 )

- copy the dates of assembly from column B of Figure 5 and paste them in the first column of the aforesaid Excel sheet under the preceding dates, insert in the second column the letter "d", insert in the third column the number "1", in the fourth column the corresponding serial numbers and in the fifth column the corresponding dressing time (they must be retrieved from column $G$ of Figure 5)

- the resulting five columns must be ordered by selecting them and sorting them in increasing order in comparison with the first column. If, on the same date, a "shipment" event and a "delivery" event occur simultaneously, the increasing order is established using the second column.

\subsection{Simulation through INVADAPT}

To begin the simulation, in the Command Window of MatLab, the word "Invadapt" must be written and the "enter" key clicked. In the Command Window all information related to the part-number to be simulated must be inputted. The first information to be input is the name of the part-number to simulate, then the date at which the simulation must start: 1st January 2000 (it must be input using the format 01-jan-2000).

Subsequently, the purchase cost of the CBN grinding wheel must be inputted. In the same way, the following information must be inputted: dressing cost, planned demand rate (given by the ratio between the planned number of pieces to produce "P" and the average life of the grinding wheel " $G$ "), initial on-hand inventory (number of grinding wheels that are available at the start of the simulation), and number of grinding wheels that have been sent to dressing before the start of the simulation (the starting date inputted in the Command Window), and that have not been yet delivered. Between an information item and the following, the "enter" key must be clicked.

After having inputted all these information items "enter" is pressed once again. The request "event date" appears on screen where the information related to the first event must be inputted: the date of the event (must be inputted using the format 01-jan-2000), the type of event ("shipment" if the grinding wheel is worn out, "delivery" if the dressed grinding wheel is delivered), the number of grinding wheels related to such event.

By pressing the "enter" key, a number of rows equal to the number of grinding wheels for the event appear. In these rows the serial numbers must be inputted and, in case of delivery, an equal number of rows also appear where the corresponding dressing cycle times must be inputted.

The system, on the basis of these information, makes the decision related to the management of the worn out CBN grinding wheels. 


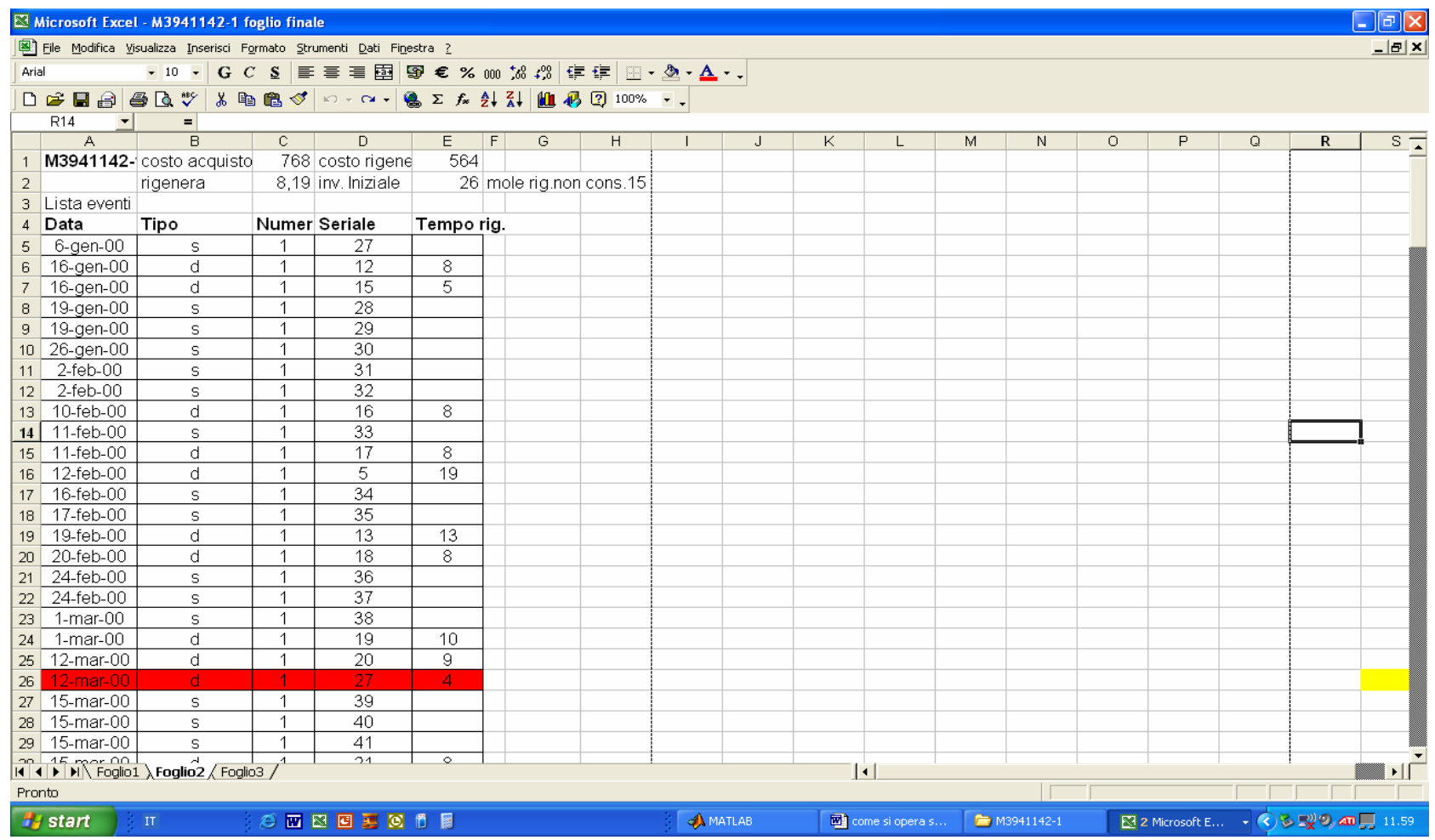

Figure 11: The rows in red have been coloured to indicate that they must not be considered during smulation.

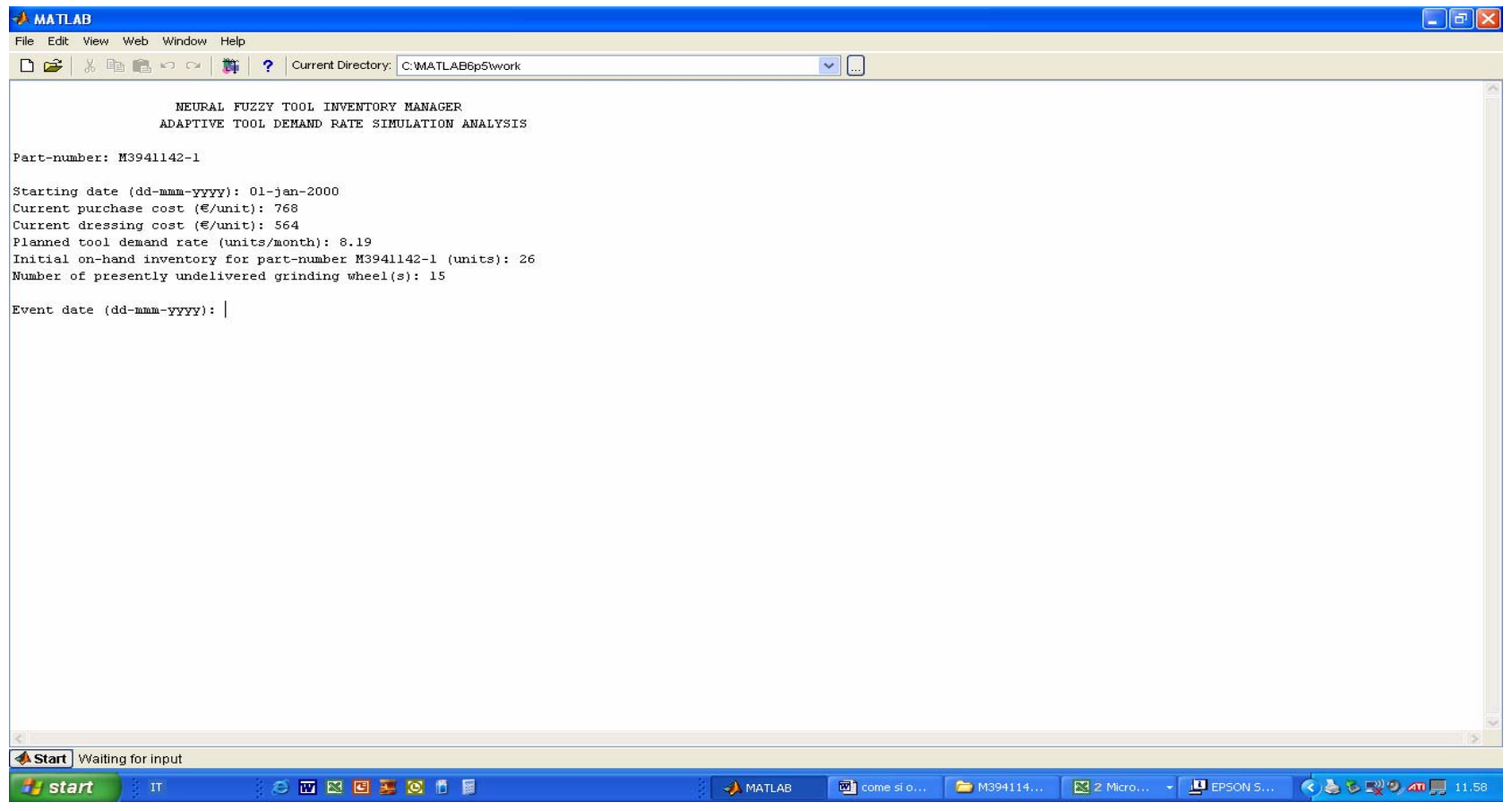

Figure 12: Input of initial data into the Command Window.

An example of simulation and the operations that must be carried out to transform the historical list into the adaptive one $^{3}$ are reported in the following. A special sheet must be built by copying the "events list" of Figure 11 for convenience. All the changes to the events list during the simulation will be made in this sheet (in this way, the original information will not be lost). The simulation starts by inputting the initial data in the Command Window (Figure 12). After inserting the first event (grinding wheel serial number 27 of row 5 in Figure 11), the next event is inserted (grinding wheel serial number 12 of row 6 in Figure 11) as shown in Figure 13. By pressing the "enter" key, the software decides if the grinding wheel must be sent to an external supplier for dressing or kept "on hold" in the tool warehouse. If it is decided to keep the grinding wheel S/N 27 "on hold" in the warehouse, in the sheet of Figure 11 the row related to the delivery event ( $d$ in the type column) of grinding wheel S/N 27 (Figure 11, row 26 in red) must be cancelled. Likewise, by proceeding to the next event it can be observed that also grinding wheels S/Ns 28 and 29 are kept "on hold" (Figure 14).

\footnotetext{
${ }^{3}$ Adaptive list: the original file of Figure 11 modified according to the decisions of the FTMS.
} 


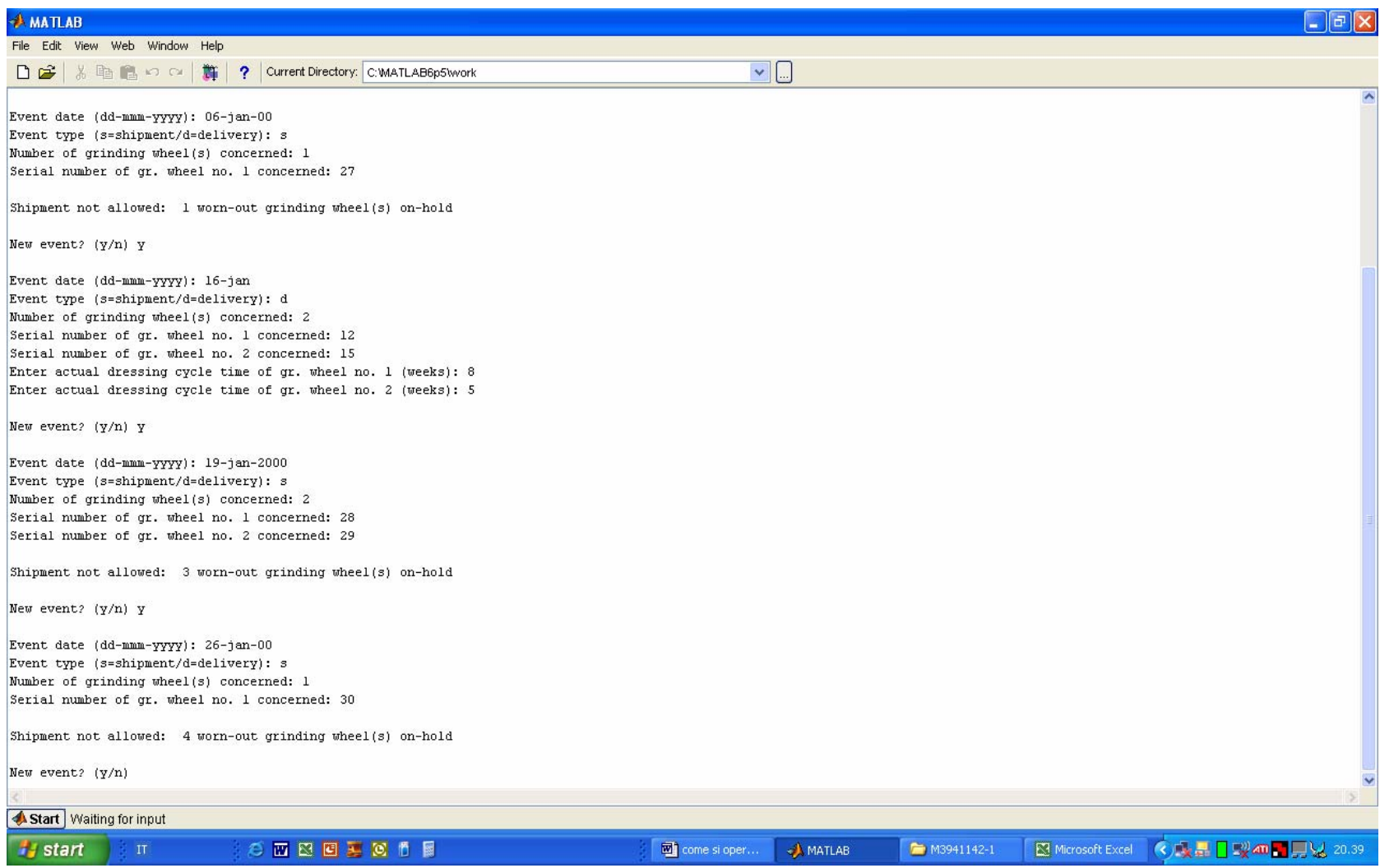

Figure 13: Input of event information into the Command Window and response from the system for S/N 27.

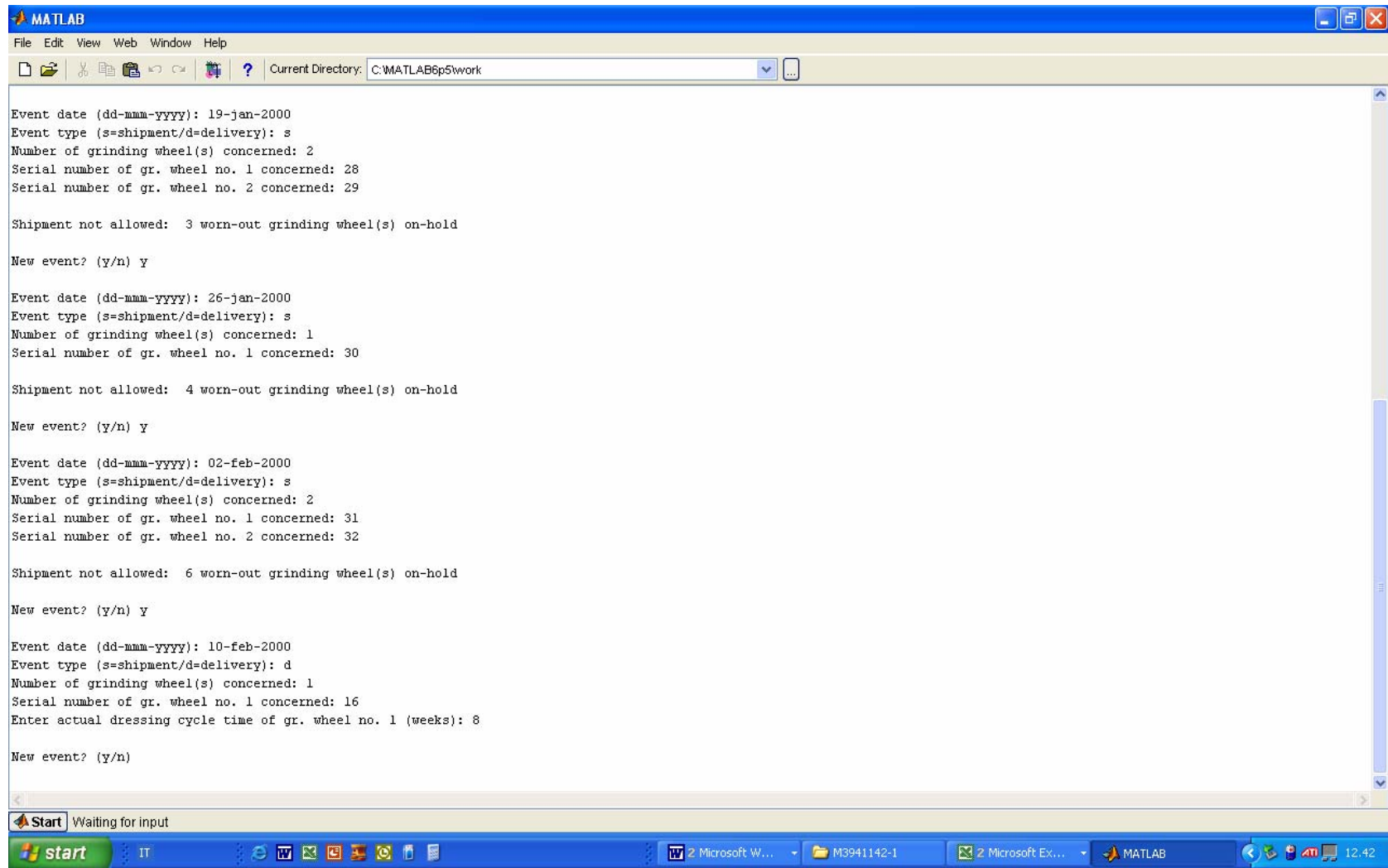

Figure 14: Event info input into the Command Window and system response for S/Ns 28, 29, 30, 31, $32,16$.

For the event dated 10th February 2000 related to worn out grinding wheel $S / \mathrm{N} \mathrm{16}$, the software decides to send it to dressing (pointing out the date at which it is predicted to be available again). In this case, the sheet of Figure 11 is not modified.
The event dated 13th April 2000 (related to grinding wheel S/Ns $47,48,49,50,51$ of rows $44,45,46,47,48$ in Figure 11) at which the shipment of grinding wheel S/Ns $47,48,49,50,51$ occurs is inputted. The software takes the decisions reported in Figure 15. 


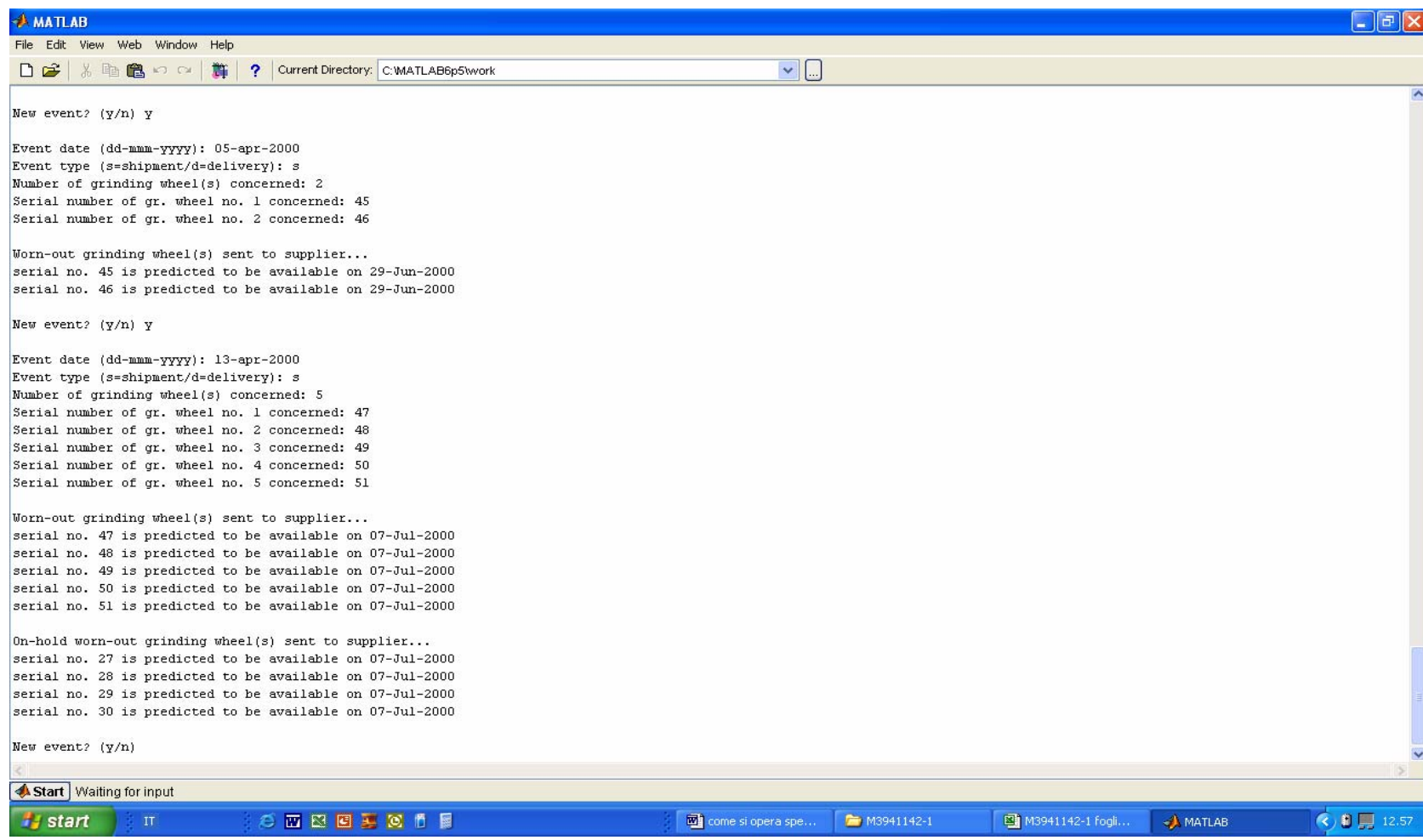

Figure 15: Event info input into the Command Window and system response for S/Ns 27, 28, 29, 30, 47, 48, 49, 50, 51.

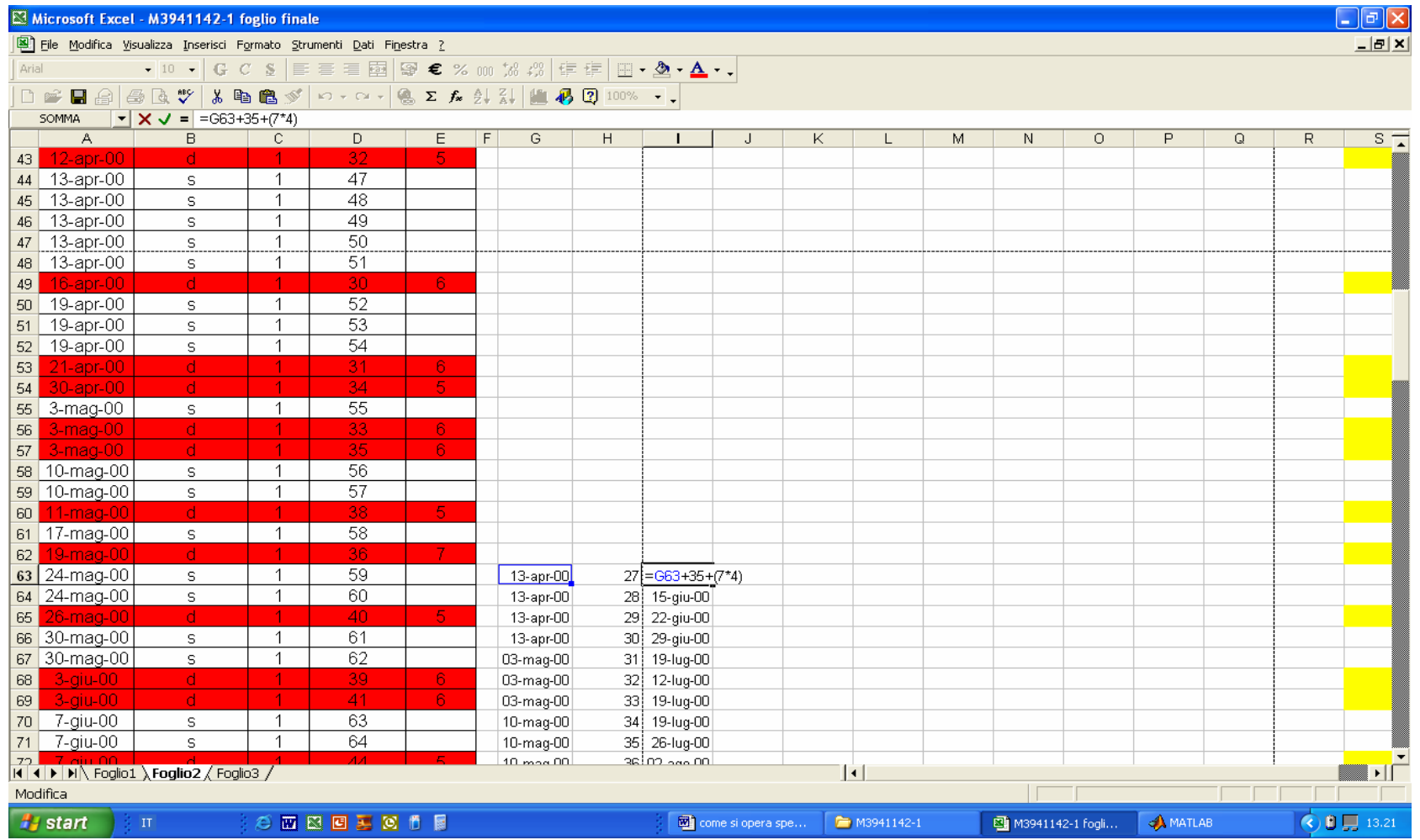

Figure 16: Actual return time calculation.

From Figure 15, it can be noted that INVADAPT decided to send for dressing not only the worn out grinding wheels $47,48,49,50,51$, but also the grinding wheels that were kept "on hold" 27, 28, 29, 30, pointing out the date at which they are predicted to be available again.

Therefore, the date at which grinding wheels 27, 28, 29, 30 will return must be calculated: to the date of actual shipment (it does not coincide with the disassembly date) the corresponding dressing cycle time and the internal time must be added.

The "internal time" is the time interval between the grinding wheel delivery from the supplier and the assembly date: in our case, this time is equal to five weeks and is considered constant. 


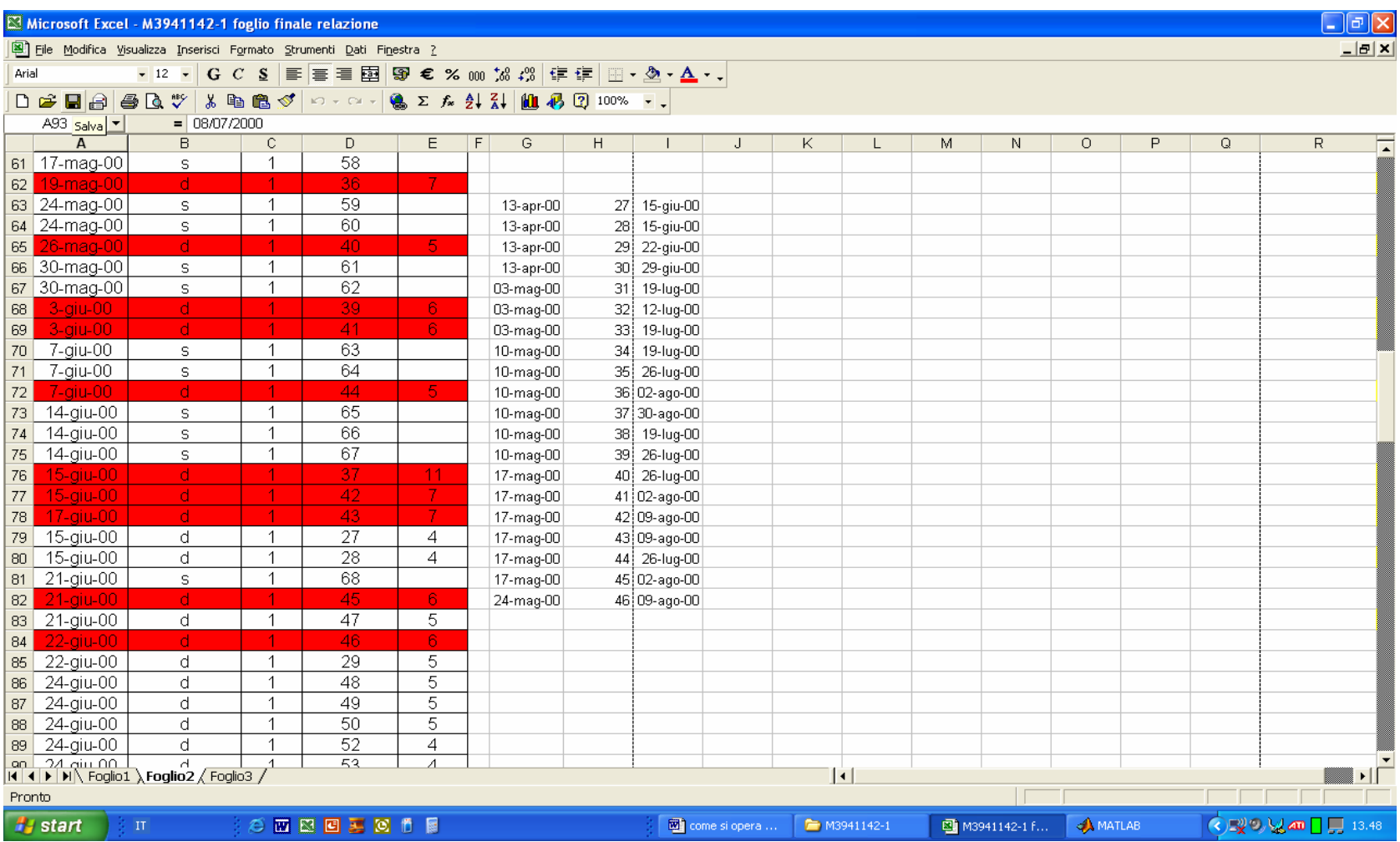

Figure 17: Sheet of Figure 11 after updating.

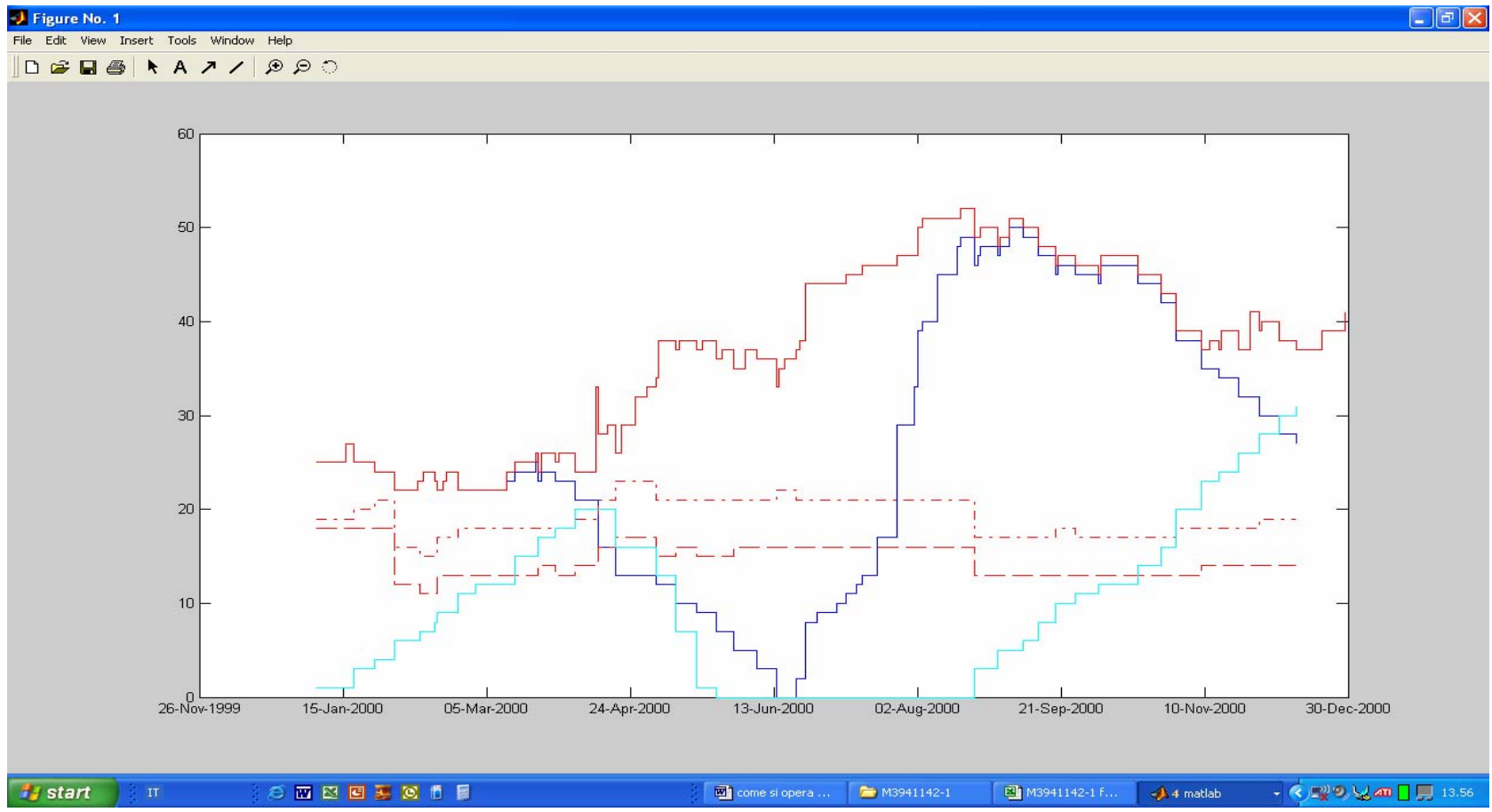

Figure 18: CBN grinding wheel inventory trend for P/N M3941142-1.

Then, the actual shipment dates for S/Ns 27, 28, 29, 30 do not coincide with the historical shipment dates of $S / N s$ $27,28,29,30$. The dates must be read in column $A$, rows 7-9 of the file in Figure 11: $6^{\text {th }}$ January $2000(27), 19^{\text {th }}$ January $2000(28,29), 26^{\text {th }}$ January $2000(30)$.

By adding to the dates of actual shipment the dressing cycle time related to each $\mathrm{S} / \mathrm{N}$ (retrieved from Column $\mathrm{E}$ of the file in Figure 11) and the internal time equal to 5 weeks, the obtained dates are: $15^{\text {th }}$ June $2000(27,28)$, $22^{\text {nd }}$ June $2000(29)$ and $29^{\text {th }}$ June 2000 (30) (Figure 16).
In the adaptive list, four rows related to the delivery events of S/Ns 27, 28, 29, 30, are added by modifying the historical list of events that coincides with the updated sheet in Figure 17. The rows related to this last operation are rows 79, 80, 85, 86 of Figure 17.

All the other events are dealt with in this way, observing that INADAPT, on $3^{\text {rd }}$ May 2000 , decides to purchase a new grinding wheel (it also happens on $10^{\text {th }}$ May 2000, $17^{\text {th }}$ May 2000 and $24^{\text {th }}$ May 2000). After the last event, at the end of the simulation, the $\mathrm{P} / \mathrm{N}$ inventory level trend is graphically visualized as in Figure 18. 


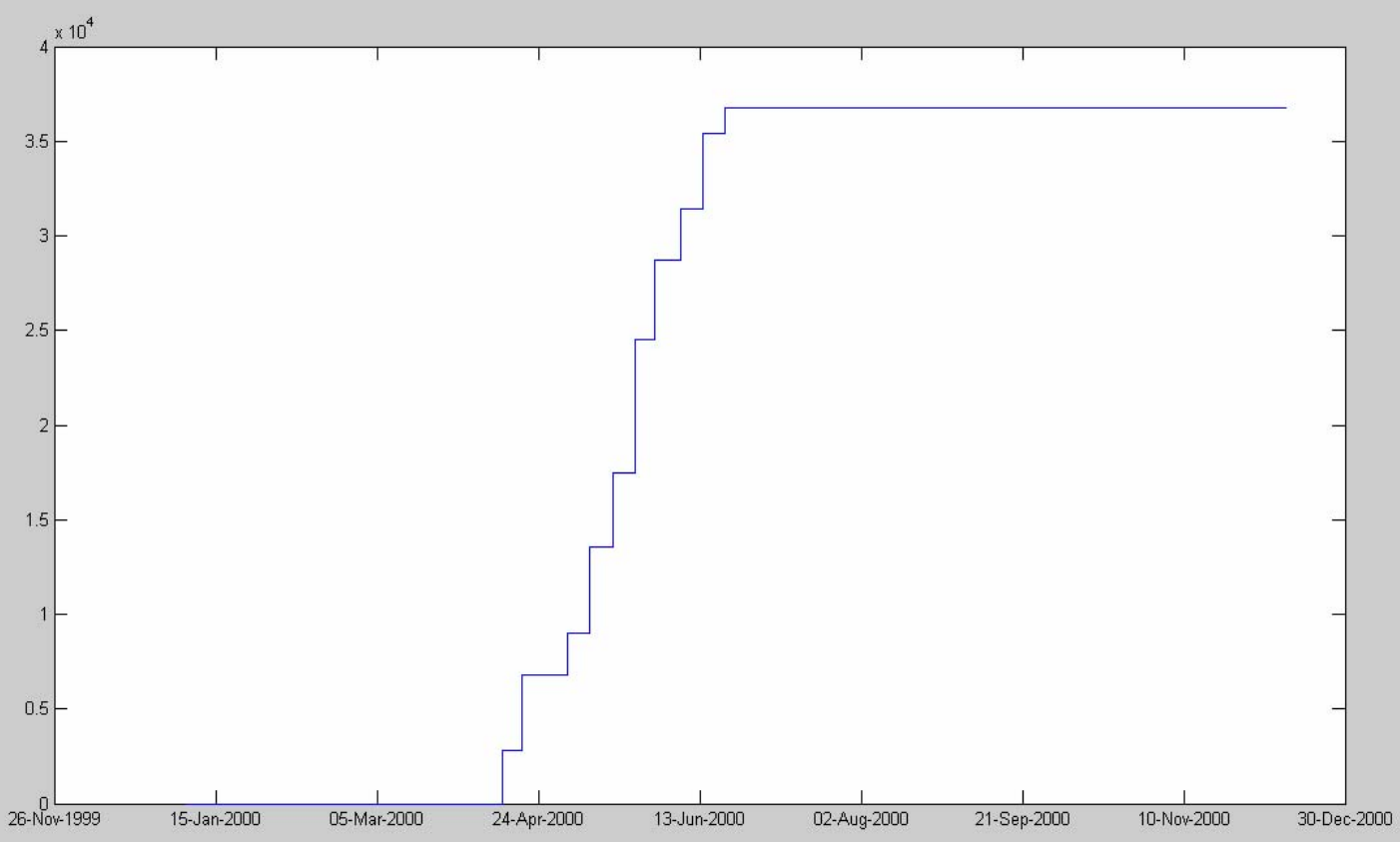

Figure 19: Tool supply cost plot for P/N M3941142-1.

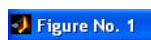

File Edit Yiew Insert Tools Window Help

回曰昌昌A

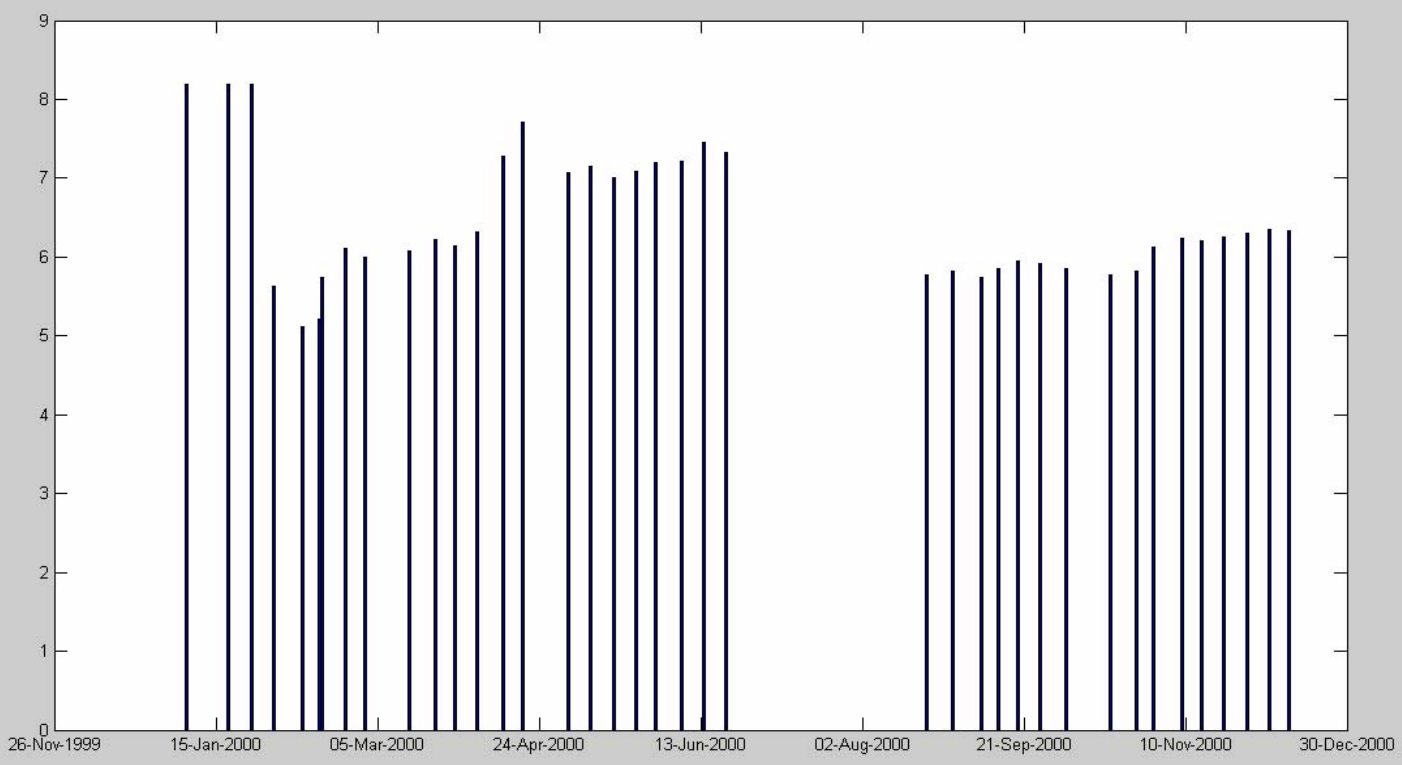

Figure 20: Adaptive tool demand rate plot for P/N M3941142-1.

This figure allows for the comparison of the simulated inventory level trend I of the INVADAPT management with the historical trend and also reports the two inventory level control range limits $I_{\min }$ and $I_{\max }$.
INVADAPT also visualizes the plot of the "tool supply cost", reported in Figure 19, and the plot of the "adaptive tool demand rate" values, reported in Figure 20. 


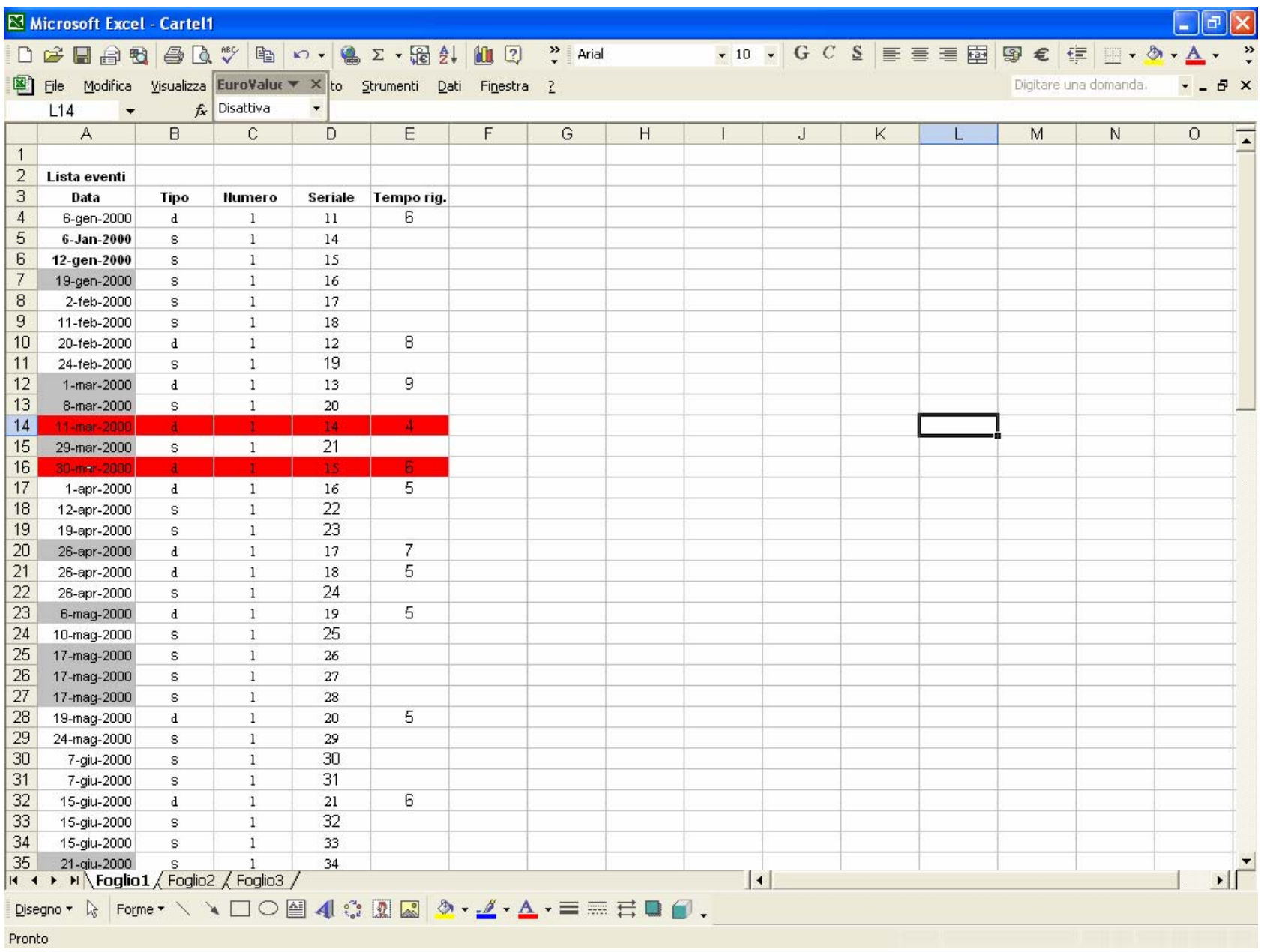

Figure 21: The rows in red have been coloured to indicate that they must not be considered during simulation.

\subsection{Simulation through I-FUTURE}

To begin the simulation, in the main screen of Invadapt, click on the box "new simulation". The initialization window appears in which all the information related to the part-number to be simulated must be inputted. The first information item to be inputted is the start date of the simulation: 1st January 2000. Then, a combo box can be opened where the part-number to simulate is selected.

Subsequently, pressing the tab key, the text box appears in which the purchase cost of the CBN grinding wheel is inputted. In the same way, the following information must be inputted: dressing cost, planned demand rate (given by the ratio between the planned number of pieces to produce " $P$ " and the average life of the grinding wheel "G"), initial on-hand inventory (number of grinding wheels that are available at the start of the simulation), and number of grinding wheels that have been sent to dressing before the start of the simulation (the starting date inputted in the Command Window), and that have not been yet delivered. After having inputted these information items press "OK". The window "event information" appears in which the information related to the first event is inputted: the date of the event (must be inserted in the international format, for example 1-jan2000), the type of event ("shipment" if the grinding wheel is worn out, "delivery" if the dressed grinding wheel is delivered), the number of grinding wheels related to such event.
By pressing the tab key, a number of rows equal to the number of grinding wheels for the event appear. In these rows the serial numbers must be inputted and, in case of delivery, an equal number of rows also appear where the corresponding dressing cycle times must be inputted. The system, on the basis of these information, makes the decision related to the management of the worn out CBN grinding wheels. An example of simulation and the operations that must be carried out to transform the historical list into the adaptive one ${ }^{4}$ are reported in the following.

The best practice is to build a special sheet copying the "events list" of Figure 21. All the changes to the events list during the simulation will be made in this sheet (in this way, the original information are not lost).

The simulation starts by inserting the initial data in the initialization window (Figure 22).

After inserting the first event (grinding wheel serial number 11 of row 4 in Figure 21), we proceed to the next one (grinding wheel serial number 14 of row 5 in Figure 21 (Figure 23). By pressing the "OK" button, the software decides if the grinding wheel must be sent to dressing or kept "on hold" in the warehouse (Figure 24).

${ }^{4}$ Adaptive list: the original file of Figure 21 modified following decisions of FTMS. 


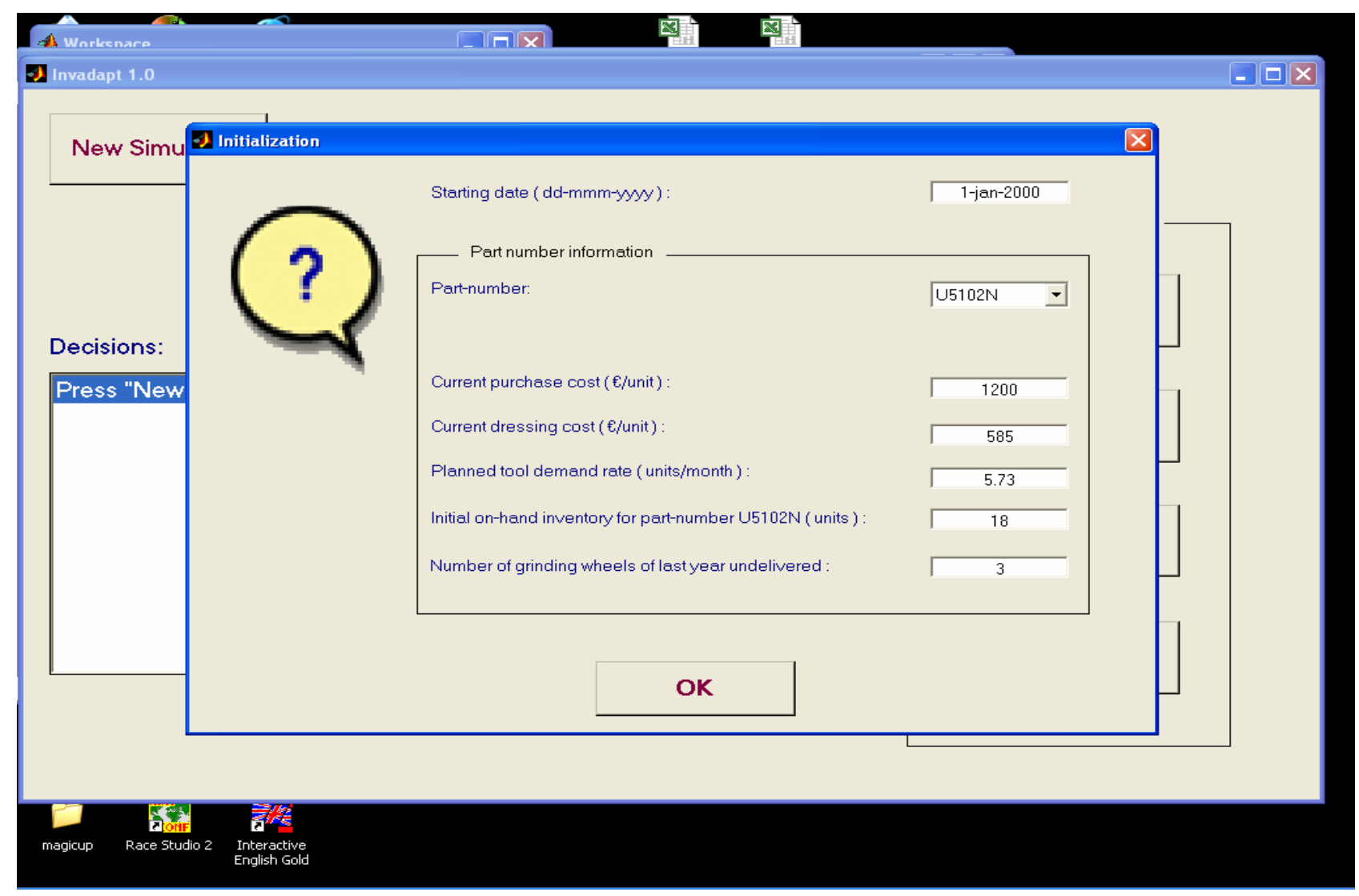

Figure 22: Initialization window for P/N U5102N.

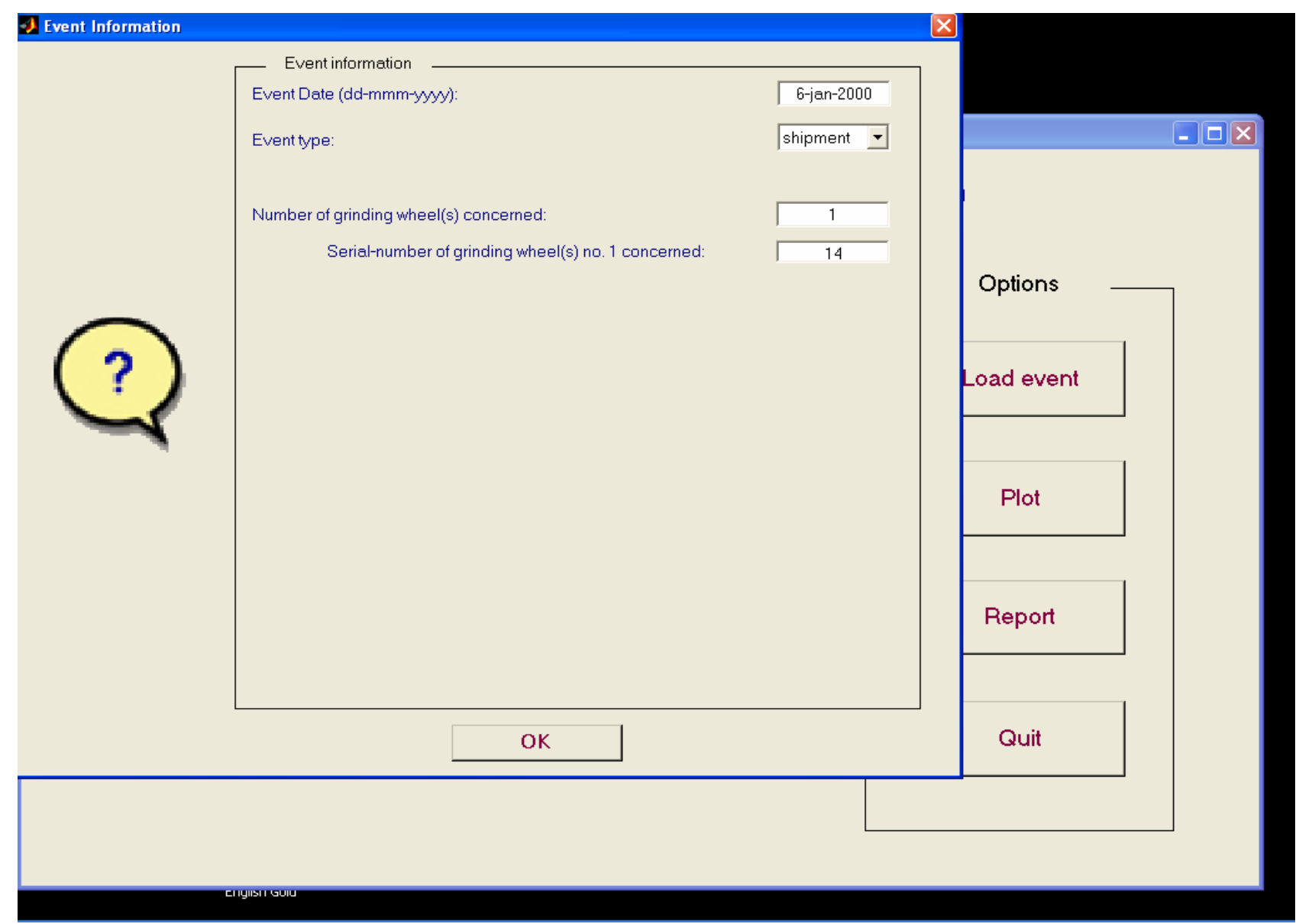

Figure 23: Event Information window for the $6^{\text {th }}$ January 2000 event related to CBN grinding wheel S/N 14. 


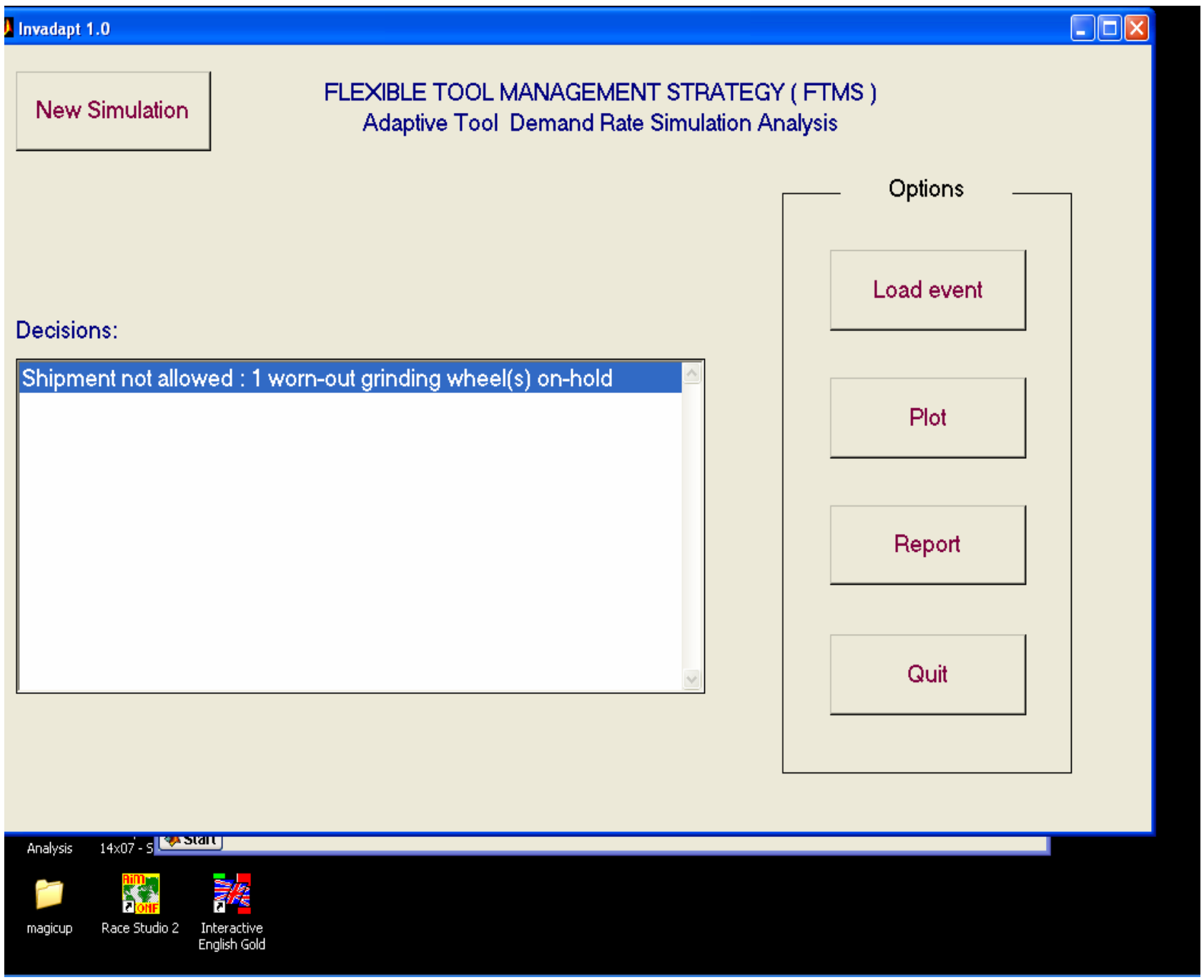

Figure 24: Decisions window for CBN grinding wheel S/N 14.

If it is decided to keep grinding wheel serial number 14 "on hold", in the sheet of Figure 21, the row related to the delivery event ( $d$ in the type column) of grinding wheel serial number 14 (Figure 21, row 14 underlined in red) must be cancelled. Likewise, we proceed to the next event observing that also grinding wheel serial number 15 is kept "on hold". The case of the event of 19 th January 2000 , related to worn out grinding wheel 16 , is different: the program decides to send it to dressing (pointing out the presumed date of availability). In this case the sheet (Figure 21) is not modified. We insert the event of 2nd February 2000 (grinding wheel serial number 17 of row 8 in Figure 21) in which the shipment of grinding wheel serial number 17 occurs, getting the decision reported in Figure 25.

The software has decided to send to dressing not only the worn out grinding wheel (17), but also the two grinding wheels that were "on hold" $(14,15)$, pointing out their date of availability.

Then the date of actual return grinding wheels 14 and 15 must be calculated: to the date of actual shipment (it does not coincide with the disassembly date) the relative dressing time and the internal time must be added.

The "internal time" is the time interval between the delivery of the grinding wheel from the supplier and the date of assembly: in our case this time is equal to five weeks and it is considered constant:
- For grinding wheel 14: the date of actual shipment coincides with the shipment date of grinding wheel 17 because the two grinding wheels depart simultaneously (the date must be read in column A, row 7 of the file in Figure 21: 2nd February 2000). To this date, the dressing time related to this grinding wheel retrieved from Column E, row 14 of the file in Figure 21 (therefore 4) and the internal time equal to 5 weeks, must be added. The obtained date is 5th April 2000 (Figure 26).

- For grinding wheel 15: the date of actual shipment coincides with the shipment of the grinding wheel 17 (it must be read in column A, row 7 of the file in Figure 8 ). To this date, the dressing time related to this grinding wheel retrieved from Column E, row 16 of the file in Figure 21 (therefore 6) and the internal time, must be added. The obtained date is 19th April 2000.

In the adaptive list, two rows related to the delivery events of grinding wheels 14 and 15 are added by modifying the historical list of events that coincides with the updated sheet in Figure 14. The rows related to this last operation are rows 17 and the 19 of Figure 27.

We proceed in this way for all the other events, observing that the software, on 27th June 2000, decides to purchase a new grinding wheel (it also happens on 19th September and 4th October 2000). At the end of the simulation, the obtained list is the list of the events related to the management implemented through the FTMS. 


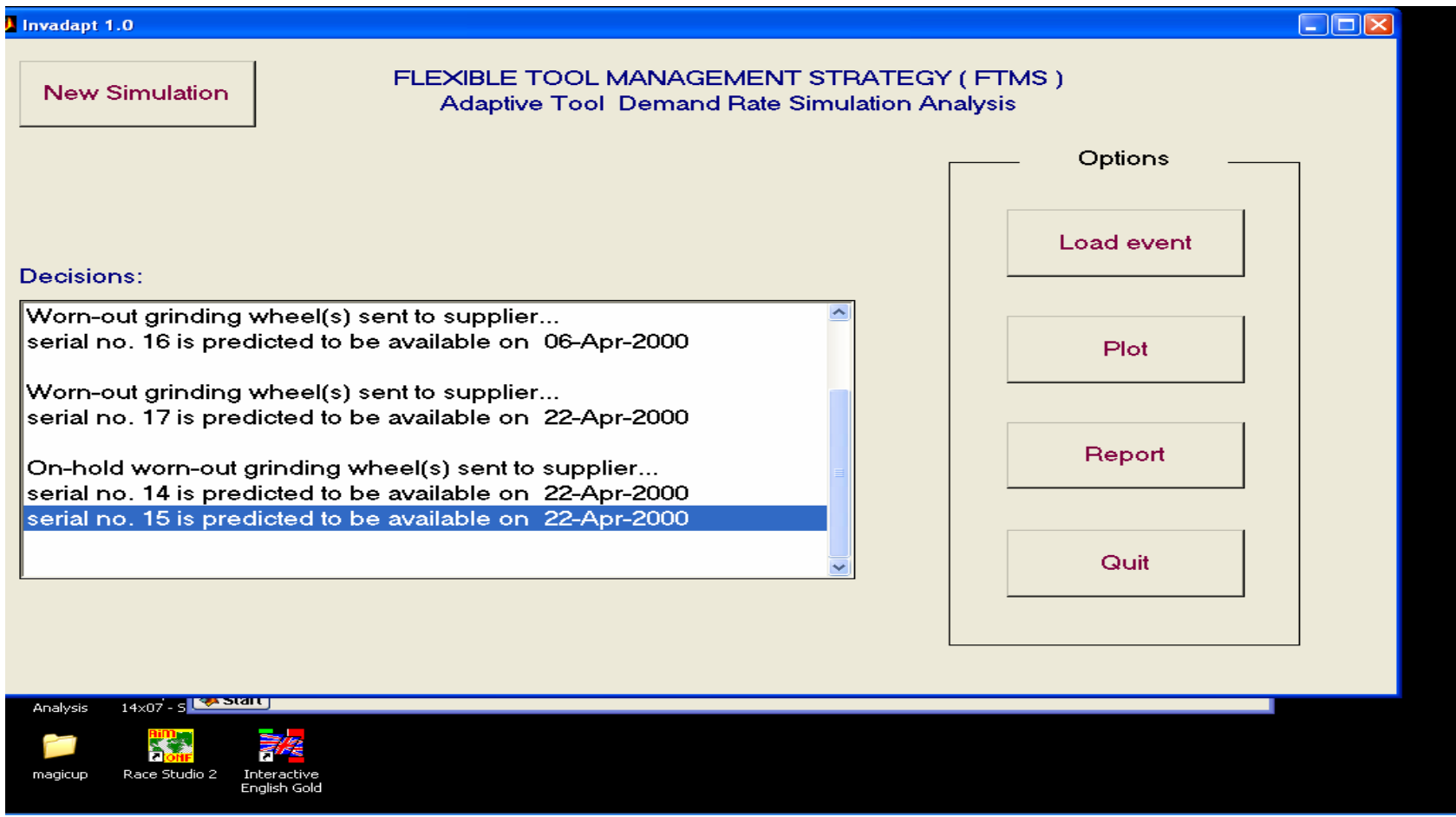

Figure 25: Decisions window for grinding wheels 14, 15, 16 and 17.

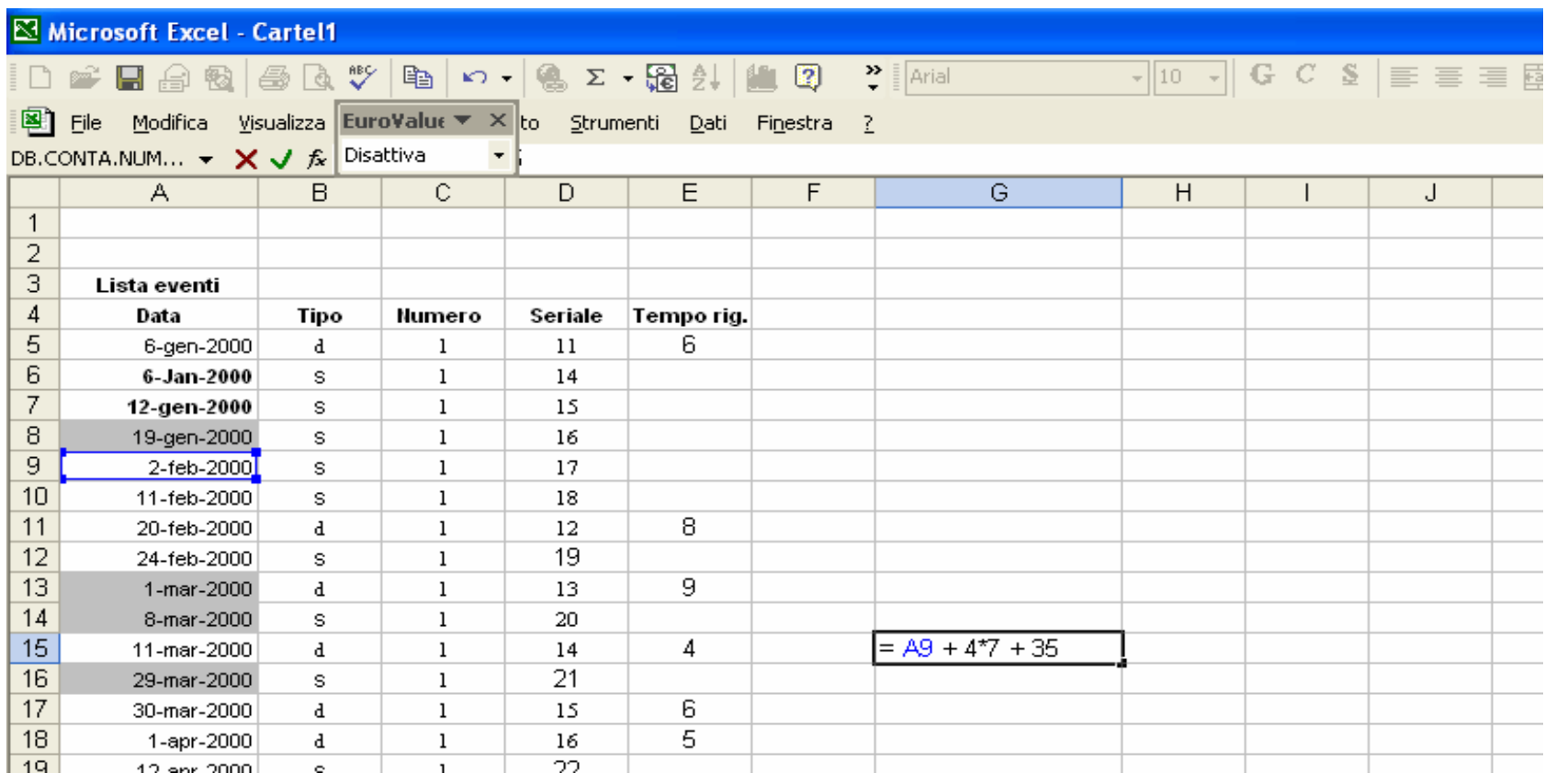

Figure 26: Actual return time calculation.

The simulated and historical inventory level can be graphically visualized by clicking the "plot" key of Figure 25 (Figure 28). This plot allows for the comparison of the simulated inventory level trend $\mathrm{I}$ of the FTMS management with the historical trend and also reports the two control range limits for the inventory level ( $I_{\min }$ and $\left.I_{\max }\right)$.Moreover, the software allows for the visualization of the "adaptive tool demand rate" plot (Figure 29).

\subsection{Simulation through INVADAPT_NS}

To begin the simulation, in the Command Window of MatLab, the word "Invadaptns" must be written and the "enter" key clicked. In the Command Window all information related to the part-number to be simulated must be inputted. The first information to be input is the name of the part-number to simulate, then the date at which the simulation must start: 1st January 2000 (it must be input using the international format 01-jan-2000).

Subsequently, the purchase cost of the CBN grinding wheel must be inputted. In the same way, the following information must be inputted: dressing cost, planned demand rate (given by the ratio among the planned number of pieces to produce " $P$ " and the average life of the grinding wheel "G"), initial on-hand inventory (number of grinding wheels that are available at the start of the simulation), and number of grinding wheels that have been sent to the dressing before the start of the simulation (the starting date inputted in the Command Window), and that have not been yet delivered. Between an information item and the following the "enter" key must be clicked. 


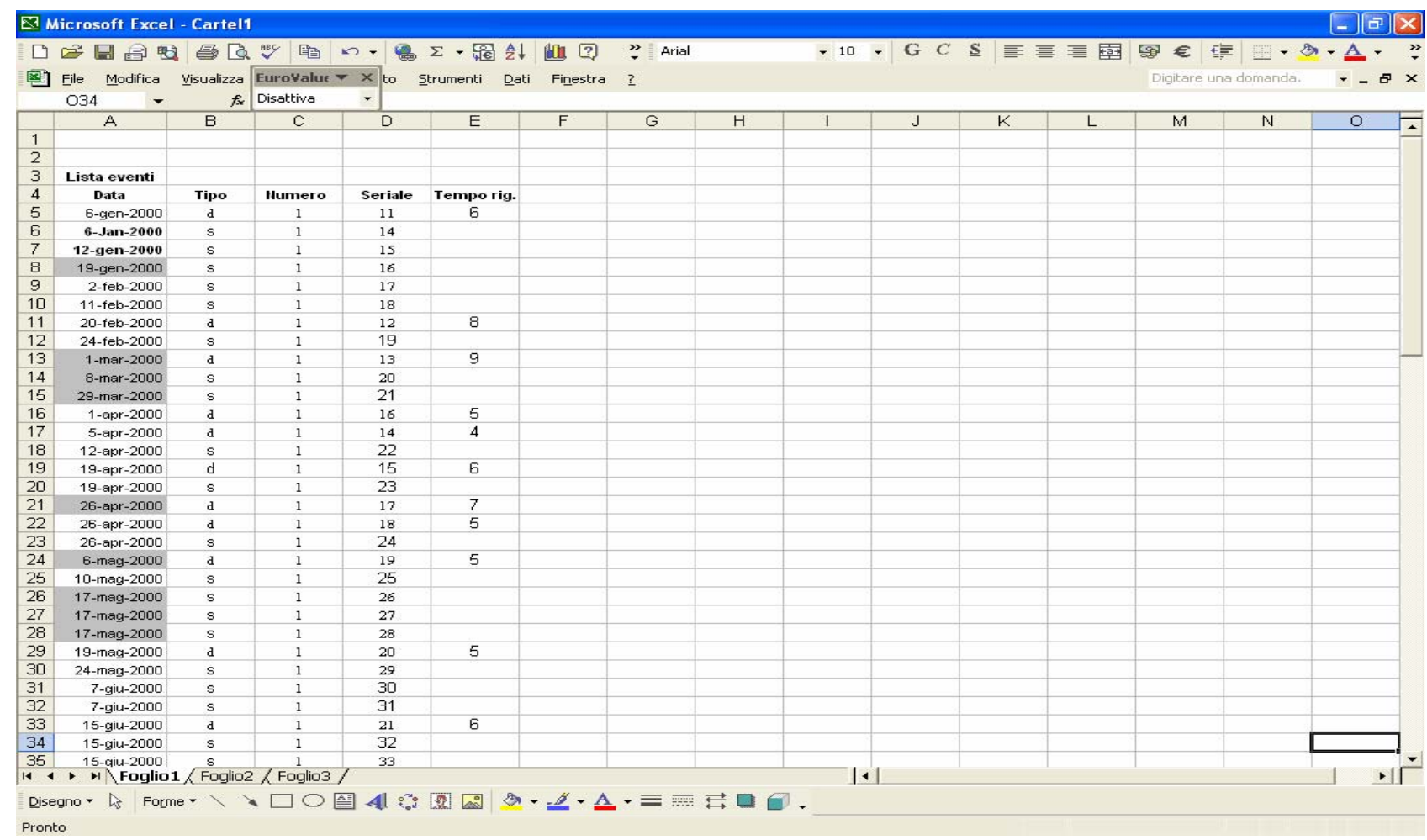

Figure 27: Excel work sheet for Figure 8 after updating.

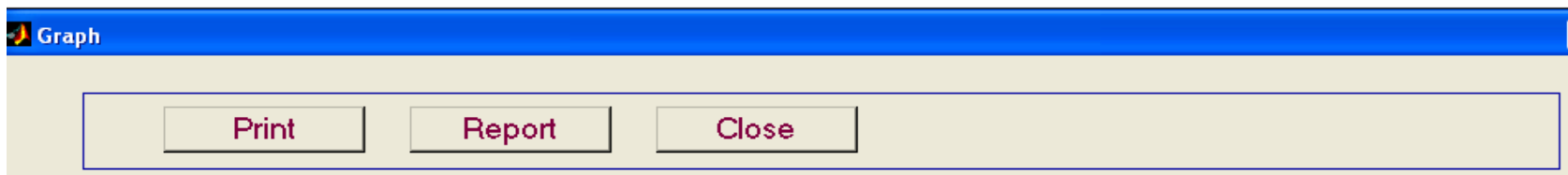

Plot historical and simulated invetory level

Update

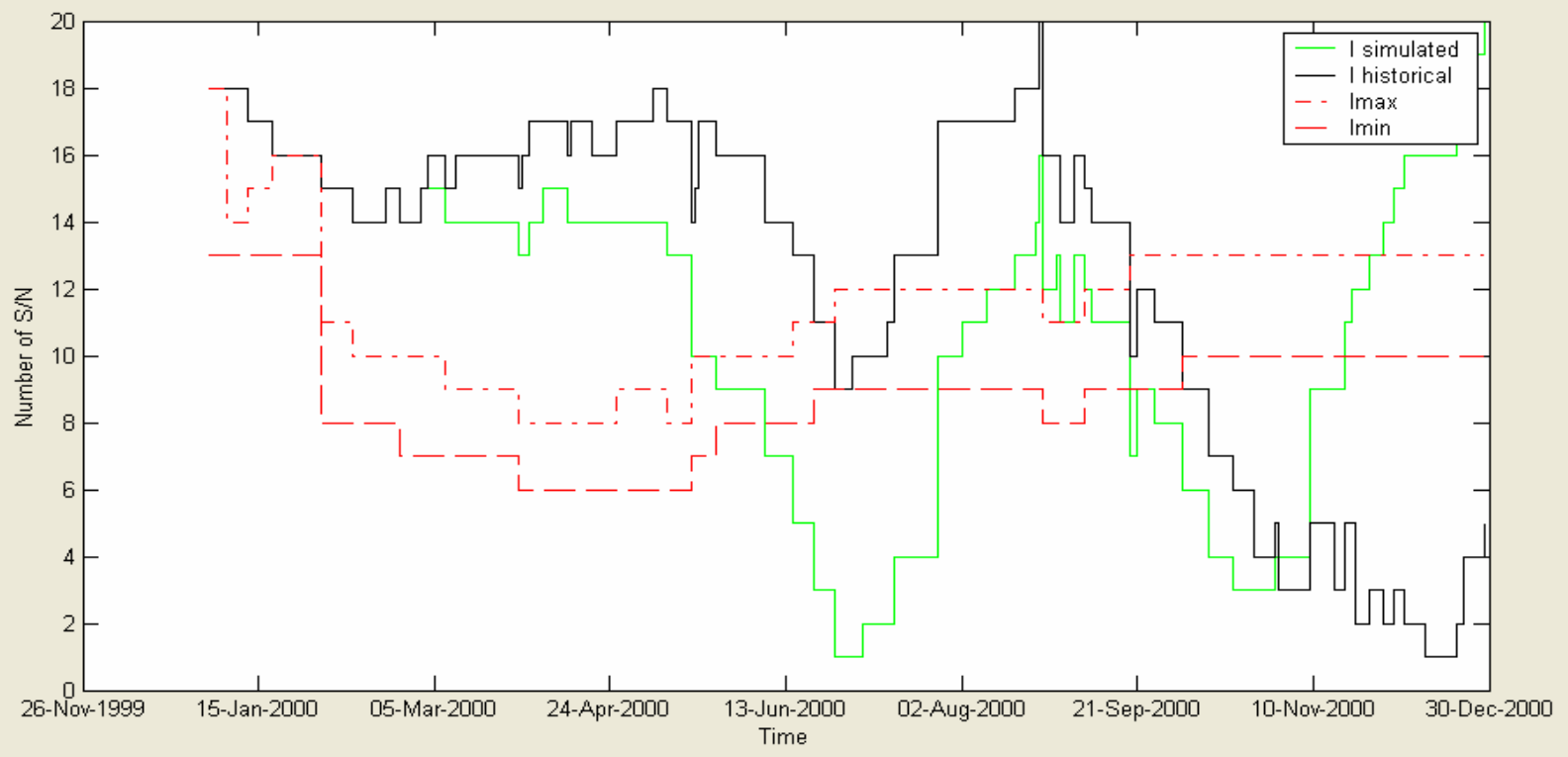

Figure 28: Historical and simulated inventory level trend.

After having inputted all these information items "enter" is pressed once again. The request "event date" appears on screen where the information related to the first event is inputted: the date of the event (must be inputted in the international format, for example 01-jan-2000), the type of event ("shipment" if the grinding wheel is worn out, "delivery" if the dressed grinding wheel is delivered), the number of grinding wheels related to such event. 


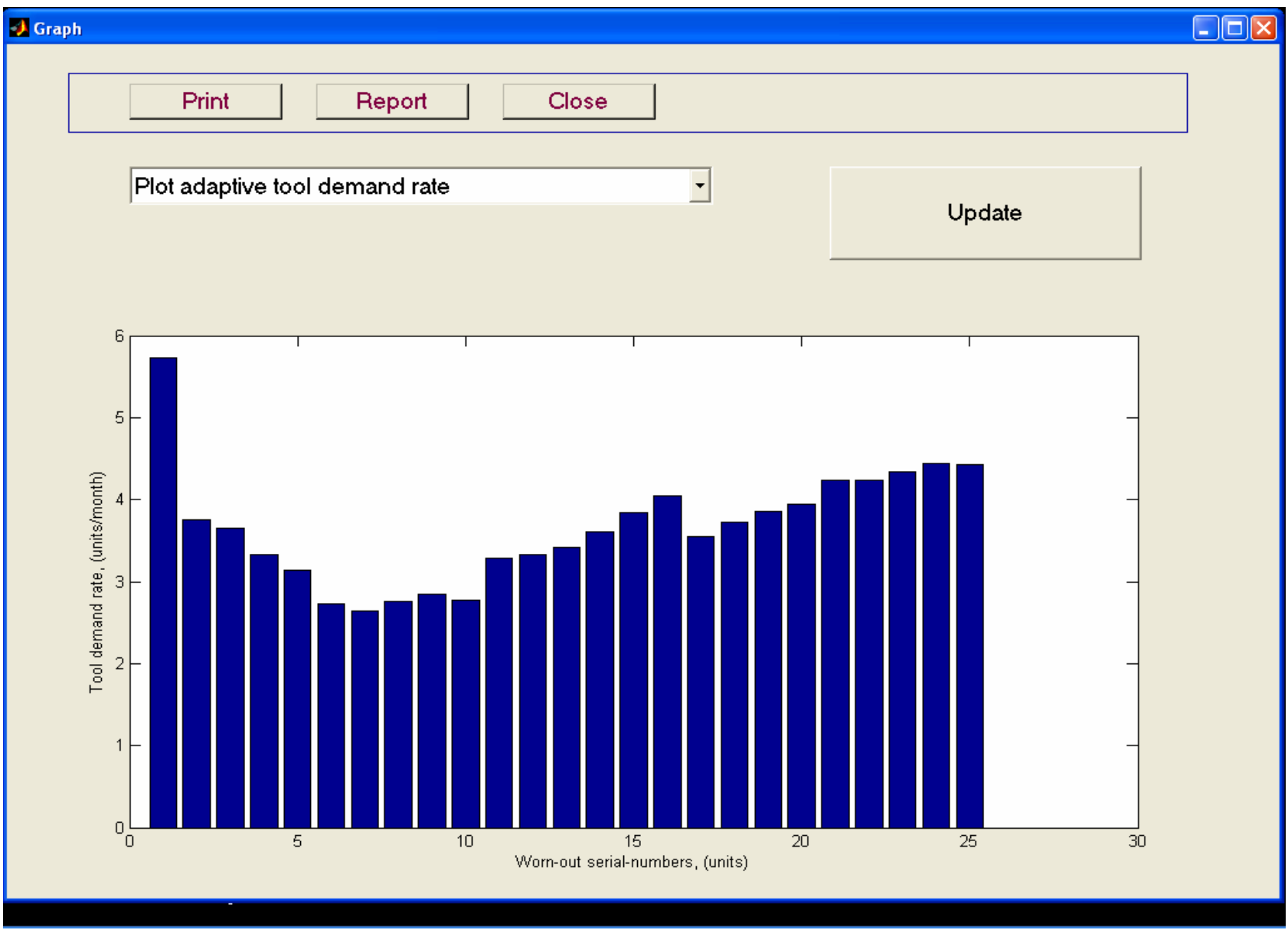

Figure 29: Adaptive demand rate plot.

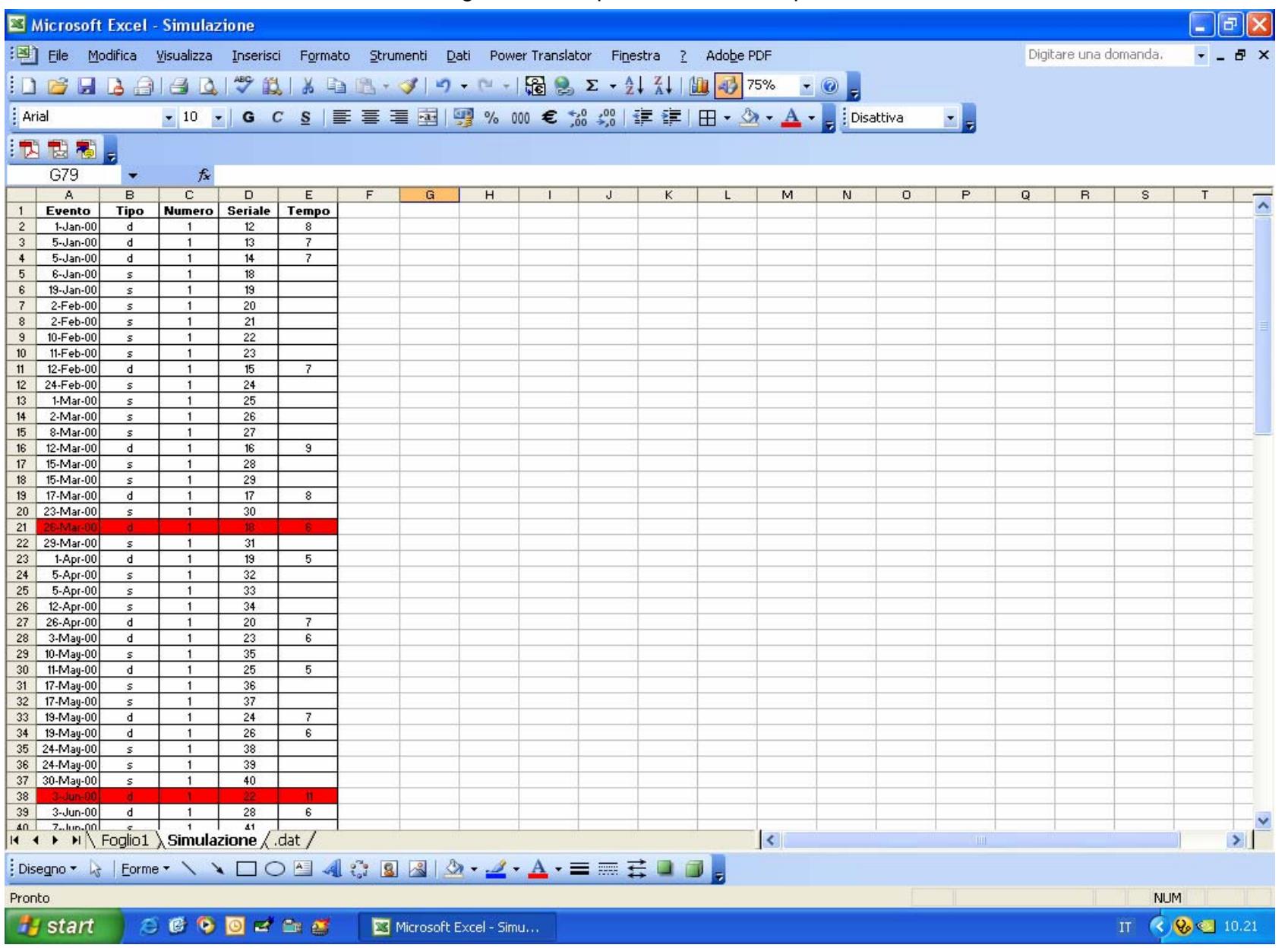

Figure 30: The rows in red have been coloured to indicate that they must not be considered during simulation. 
File Modifica Formato Visualizza ?

NEURAL FUZZY TOOL INVENTORY MANAGER
ADAPTIVE TOOL DEMAND RATE SIMULATION ANALYSIS

Part-number: $45103 \mathrm{~N}$

starting date (dd-mmm-xy): $01-j a n-2000$

Current purchase cost (€) unit): 1113

PTanned tool demand rate (units/month): 3.82

Initial on-hand inventory for part-number $15103 \mathrm{~N}$ (units): 20

Initial on-hand inventory for part-number u5103N (un
Number of present $7 y$ undelivered grinding wheel(s): 6

Event date (dd-mmm-yoy): 01-jan-2000

Number type ( $s=$ shipment/d=delivery): d

Serial number of gr. wheel no. 1 concerned: 12

Figure 31: Command Window for the $1^{\text {st }}$ January 2000 event related to CBN grinding wheel S/N 12.

U5103N - Blocco note

File Modifica Formato Visualizza ?

NEURAL FUZZY TOOL INVENTORY MANAGER

ADAPTIVE TOOL DEMAND RATE SIMULATION ANALYSIS

Part-number: $45103 \mathrm{~N}$

starting date (dd-mmm-yyy): 01-jan-2000

Current purchase cost (€/unit): 1113

Planned tool demand rate (units/month): 3.82

Initial on-hand inventory for part-number U5103N (units): 20

Number of presently undelivered grinding wheel(s): 6

Event date (dd-mmm-yyy): 01-jan-2000

Event type (s=shipment/d=delivery): d

Number of grinding wheel(s) concerned: 1

serial number of gr. wheel no. 1 concerned: 12

Enter actual dressing cycle time of gr. wheel no. 1 (weeks): 8

New event? $(\mathrm{y} / \mathrm{n}) \mathrm{y}$

Event date (dd-mmm-yyyy): $05-j$ an-2000

Event type ( $s=$ shipment/d=delivery): d

serial number of $\mathrm{gr}$. whee? no. 1 concerned.

Serial number of gr. Wheel no. 1 concerned: 13

Enter actual dressing cycle time of $\mathrm{gr}$. Wheel no. 1 (weeks) : 7
Enter actual dressing cycle time of $\mathrm{gr}$. Wheel no. 2 (weeks): 7

Figure 32: Command Window for the $5^{\text {th }}$ January 2000 event related to grinding wheels S/Ns 13,14. 


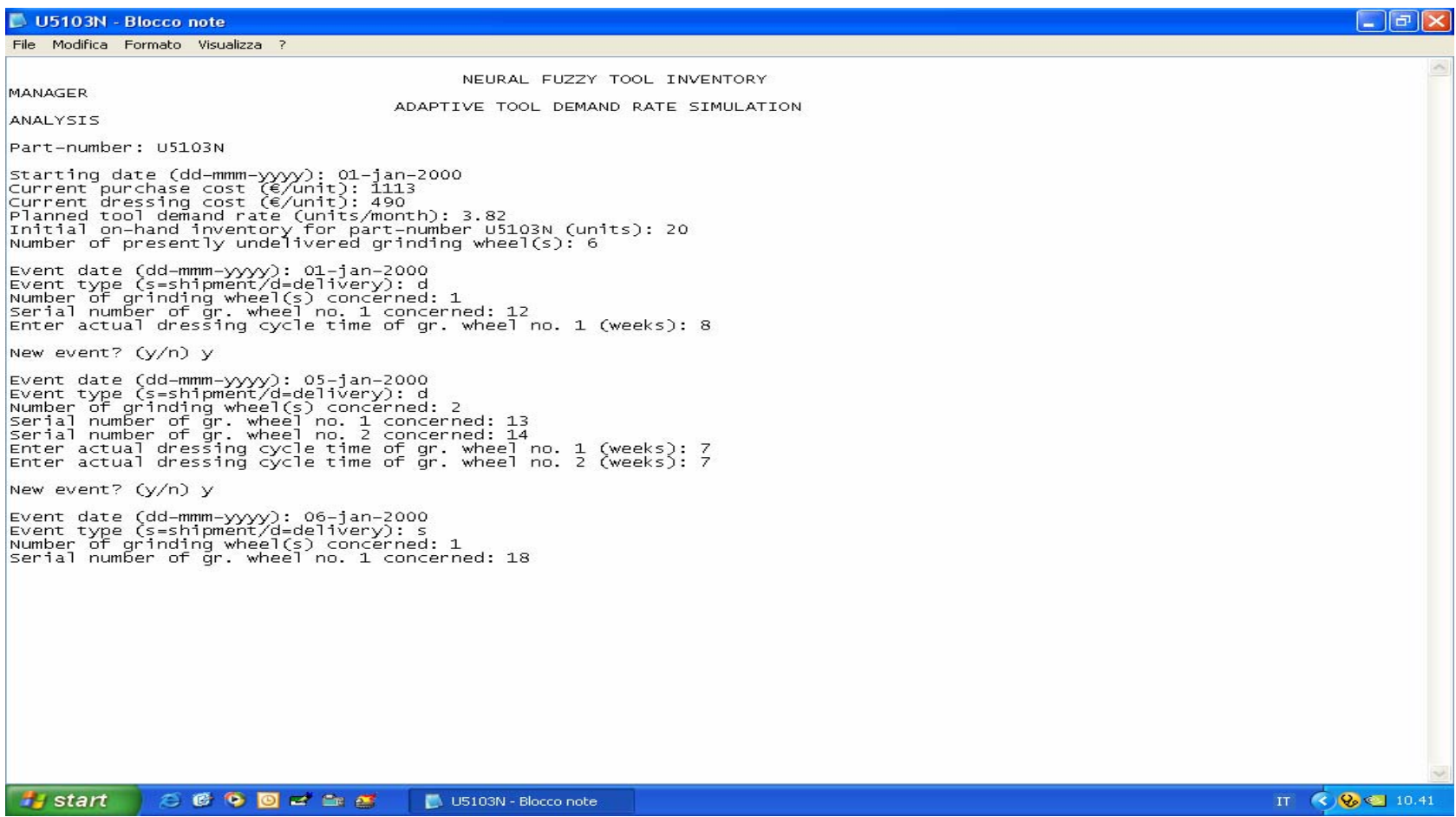

Figure 33: Command Window for the $6^{\text {th }}$ January 2000 event related to CBN grinding wheel S/N 18.

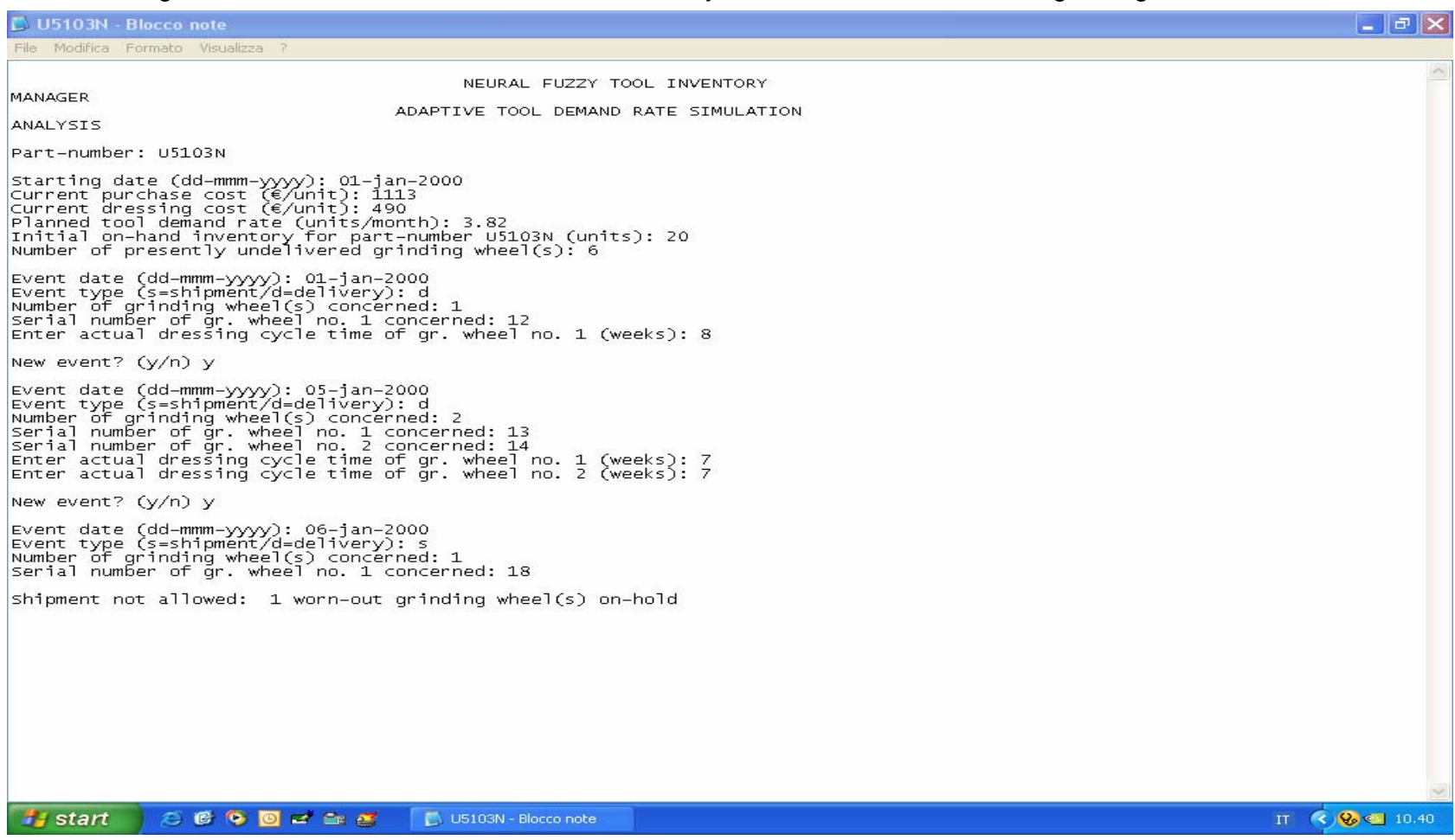

Figure 34: Command Window for the $6^{\text {th }}$ January 2000 event related to CBN grinding wheel S/N 18.

By pressing the "enter" key, a number of rows equal to the number of grinding wheels for the event appear. In these rows the serial numbers must be inputted and, in case of delivery, an equal number of rows also appear where the corresponding dressing cycle times must be inputted. The system, on the basis of these information, makes the decision related to the management of the worn out CBN grinding wheels. An example of simulation and the operations that must be carried out to transform the historical list into the adaptive one ${ }^{5}$ are reported in the following.

A special sheet must be built by copying the "events list" of Figure 30 for convenience. All the changes to the events list during the simulation will be made in this sheet (in this way original information will not be lost).
The simulation starts by inputting the initial data in the Command Window (Figure 31).

After inserting the first event (grinding wheel serial number 12 of row 2 in Figure 30), the next event is inserted (grinding wheels serial number 13 and serial number 14 of rows 3 e 4 in Figure 30).

After inserting the second and third events we proceed to the next one (grinding wheel serial number 18 of row 5 in Figure 30).

Pressing the key "enter" the software decides if the grinding wheel must be sent to an external supplier for dressing or kept "on-hold" in the tool warehouse. 


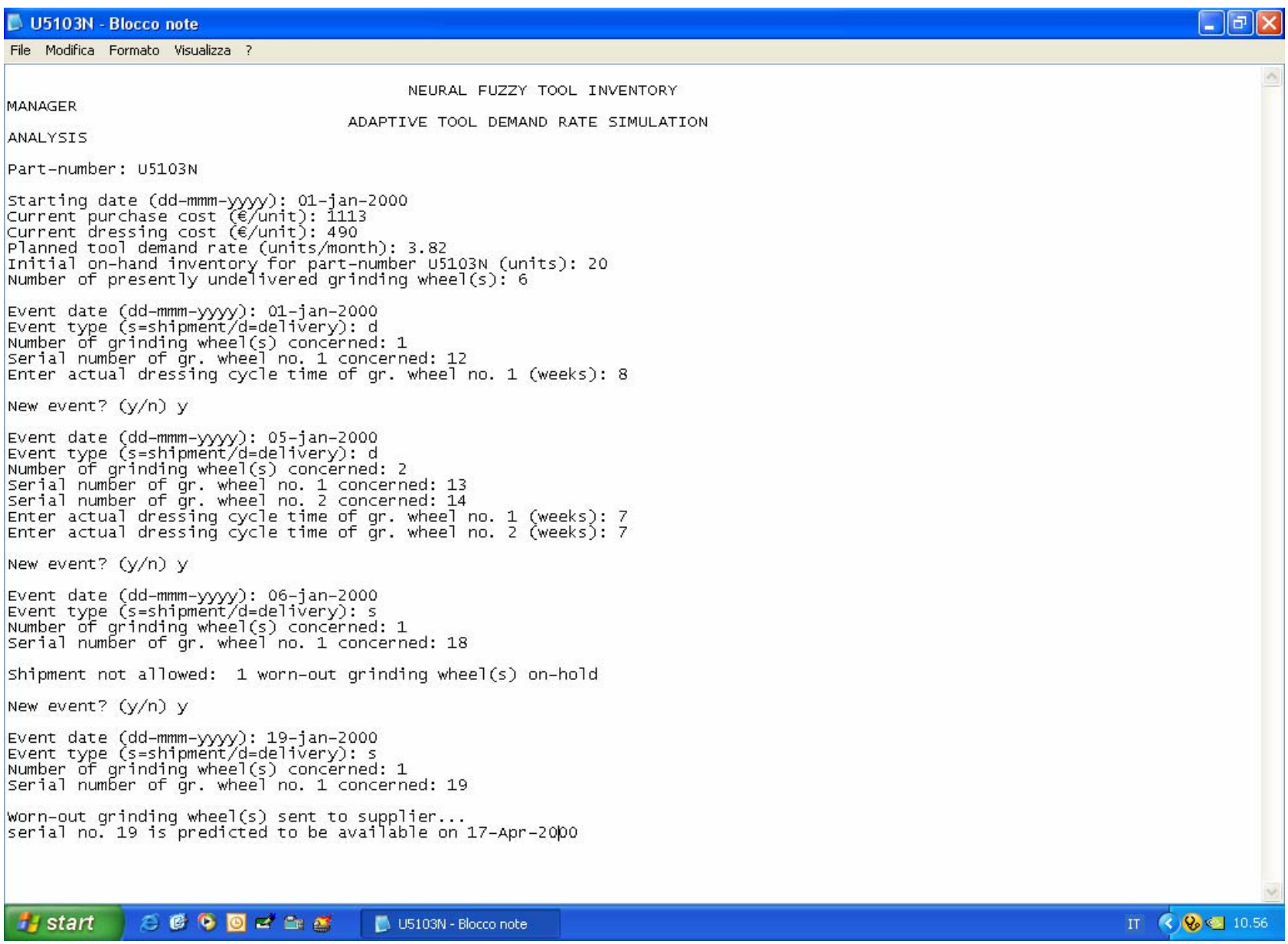

Figure 35: Command Window for the $19^{\text {th }}$ January 2000 event related to CBN grinding wheel S/N 19.

If it is decided to keep the grinding wheel serial number 18 "on hold" in the warehouse, in the sheet of Figure 30, the row related to the delivery event ( $d$ in the type column) of grinding wheel serial number 18 (Figure 30, row 21 underlined in red) must be cancelled.

The event dated $19^{\text {th }}$ January 2000 (related to worn out grinding wheel 19 of row 6 in Figure 30), at which the shipment of grinding wheel serial number 19 occurs, is inputted. The software takes the decision reported in Figure 35. From Figure 35, it can be observed that the software has decided to send to an external supplier for dressing the grinding wheel serial number 19. In this case the sheet of Figure 30 is not modified

We proceed for the next events and can be observed that also the grinding wheel serial number 22 is kept "on hold".

From Figure 36, it can be observed that the software, for the events dated $27^{\text {th }}$ June 2000 (related to the worn out grinding wheel serial numbers $43,44,45$ of rows 46,47 , 48 in Figure 37 ) has decided to send to an external supplier not only the worn out grinding wheels $43,44,45$, but also the worn out grinding wheel that was kept "onhold" (22) pointing out the date at which it is predicted to be available again. We must therefore calculate the date at which the grinding wheel 22 will return really: to the date of actual shipment (it does not coincide with the disassembly date) the corresponding dressing cycle time and the internal time must be added. The "internal time" is the time interval between the delivery of the grinding wheel from the supplier and the date of assembly: in our case this time is equal to five weeks and it is considered constant. Then, the date of actual shipment is:
- for grinding wheel serial number 22 coincides with the historical shipment dates of grinding wheels $43,44,45$. By adding to the date of actual shipment the dressing cycle time related to this grinding wheel (retrieved from Column E, row 38 in Figure 30 (therefore 11) and the internal time equal to 5 weeks, the obtained date is $17^{\text {th }}$ October 2000 (Figure 37).

In the adaptive list, one row related to delivery event of the grinding wheel 22 , is added by modifying the historical list of events that coincides with the updated sheet in Figure 38. The row related to this last operation is row 75 of Figure 37. We proceed in this way for all the other events. After the last event, at the end of the simulation, the CBN grinding wheel inventory trend is graphically visualized in Figure 39. This figure compares the simulated inventory level trend I of the FTMS management with the historical one and also reports the two control range limits for the inventory levels ( $I_{\min }$ and $\left.I_{\max }\right)$. The software also visualizes the plot of the "tool supply cost" reported in Figure 40. Moreover the software visualizes the plot of the "adaptive tool demand rate" values reported in Figure 41 . We proceed in this way for all the other events. At the end of the simulation, the obtained list is the list of the events related to the management implemented through the FTMS. After the last event, at the end of the simulation, the trend of the grinding wheels inventory is graphically visualized in Figure 38. This figure compares the simulated inventory level trend I of FTMS management with the historical one and also gives two control range limits for the inventory levels $\left(I_{\min }\right.$ and $\left.I_{\max }\right)$. 
worn-out grinding wheel(s) sent to supplier...

serial no. 41 is predicted to be available on 31-Aug-2000

New event? $(y / n) y$

Event date (dd-mmm-yyyy): 07-jun-2000

Event type (s=shipment/d=delivery): d

Number of grinding wheel(s) concerned: 3

serial number of gr. Wheel no. 1 concerned: 30

Serial number of gr. Wheel no. 2 concerned: 31

Enter actual dressing cycle time of gr. wheel no. 1 (weeks): 6

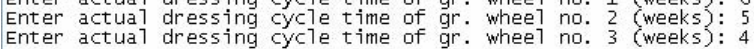

New event? $(y / n) y$

Event date (dd-mmm-yyy): $17-j u n-2000$
Event type (s=shipment/d=delivery): d

Number of grinding wheel( $(s)$ concerned: 1

serial number of gr. wheel no. 1 concerned: 29
Enter actual dressing cycle time of gr. wheel no. 1 (weeks): 8

New event? $(y / n) y$

Event date (dd-mmm-yyyy): 21-jun-2000

Event type $(s=$ shipment $/$ d $=$ delivery $): s$

Number of grinding whee1(s) concerned: 1
serial number of gr. wheel no. 1 concerned: 42

worn-out grinding wheel(s) sent to supplier...

serial no. 42 is predicted to be available on 14-5ep-2000

New event? $(\mathrm{y} / \mathrm{n}) \mathrm{y}$

Event date (dd-mmm-yysy): 27-jun-2000

Event type ( $s=$ shipment/d=delivery): s

serja 7 number of gr. wheel no. 1 concerned: 43

Serial number of gr. Wheel no. 2 concerned: 44
serial number of gr. Wheel no. 3 concerned: 45

worn-out grinding wheel(s) sent to supplier..

weria no. 43 is predicted to be avapplable $20-5 e p-2000$

serial no. 45 is predicted to be available on $20-5 e p-2000$

on-hold worn-out grinding wheel(s) sent to supplier...

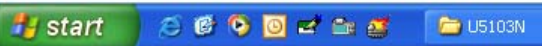

Figure 36: Command Window for the $27^{\text {th }}$ June 2000 events related to grinding wheels S/Ns 43, 44, 45.

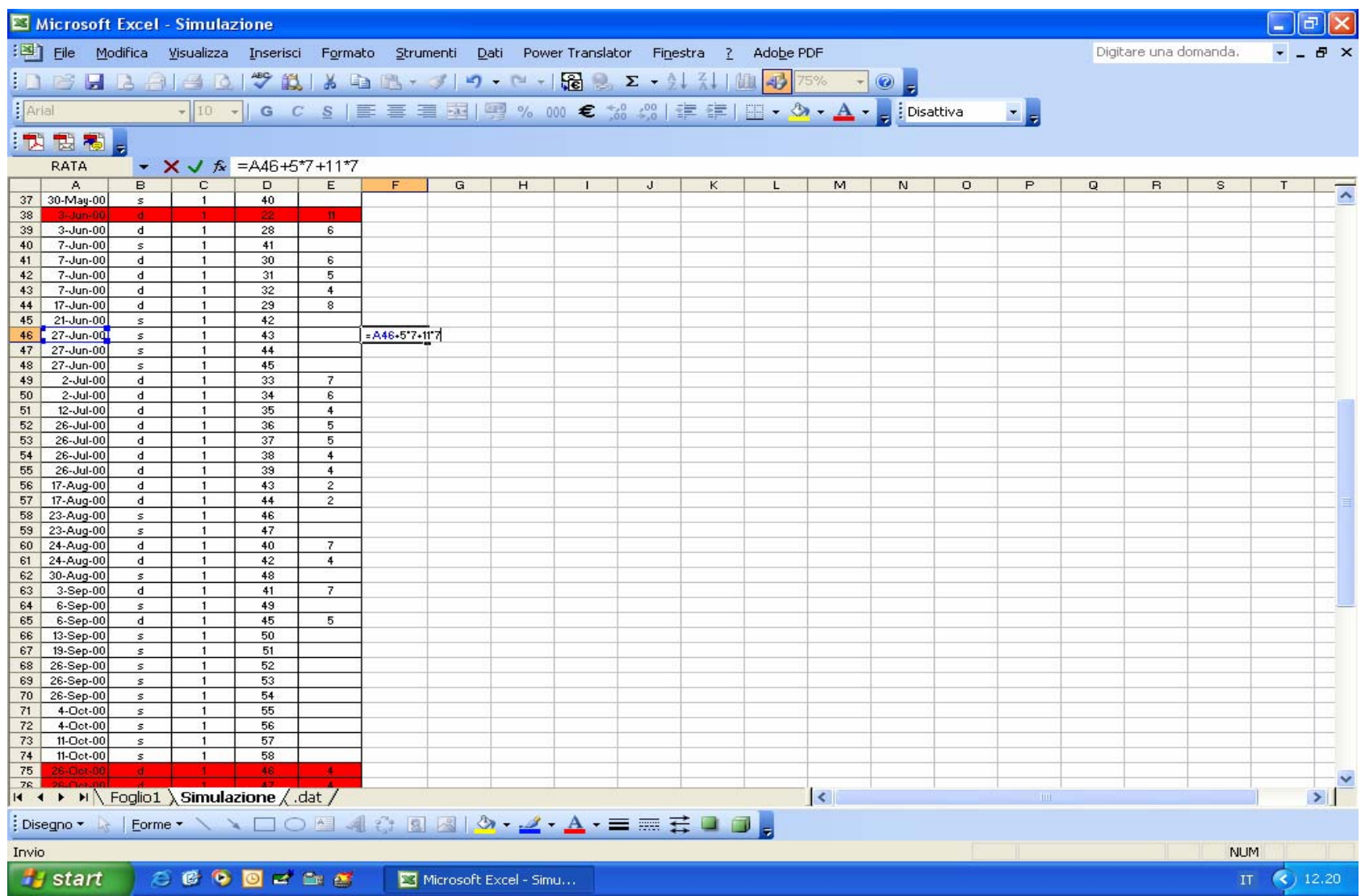

Figure 37: Actual return time calculation. 


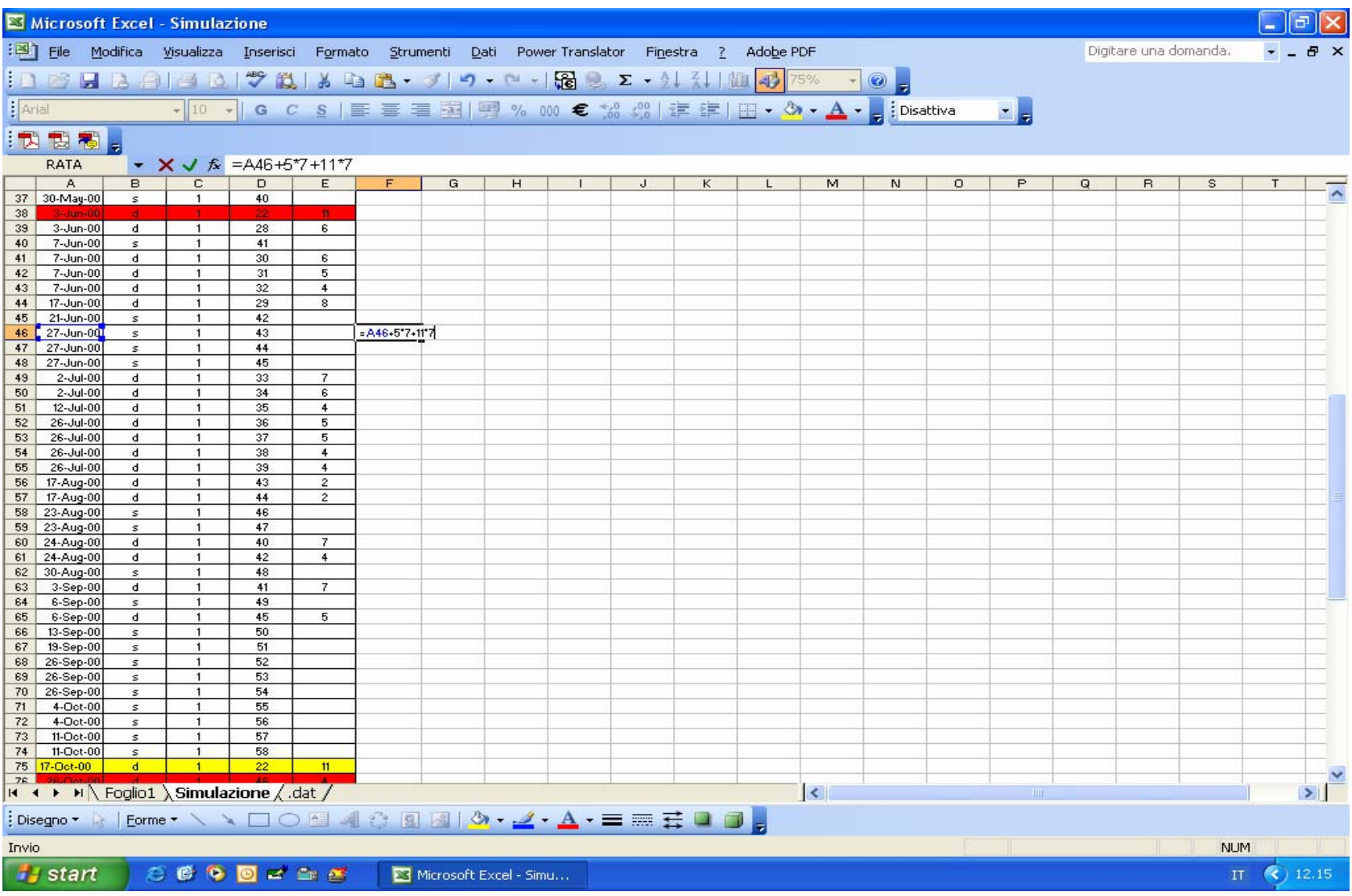

Figure 38: Excel work sheet of Figure 30 after updating.

\section{- 7 Figure №. 1}

File Edit View Insert Tools Window Help

$\|$ 口回是A A

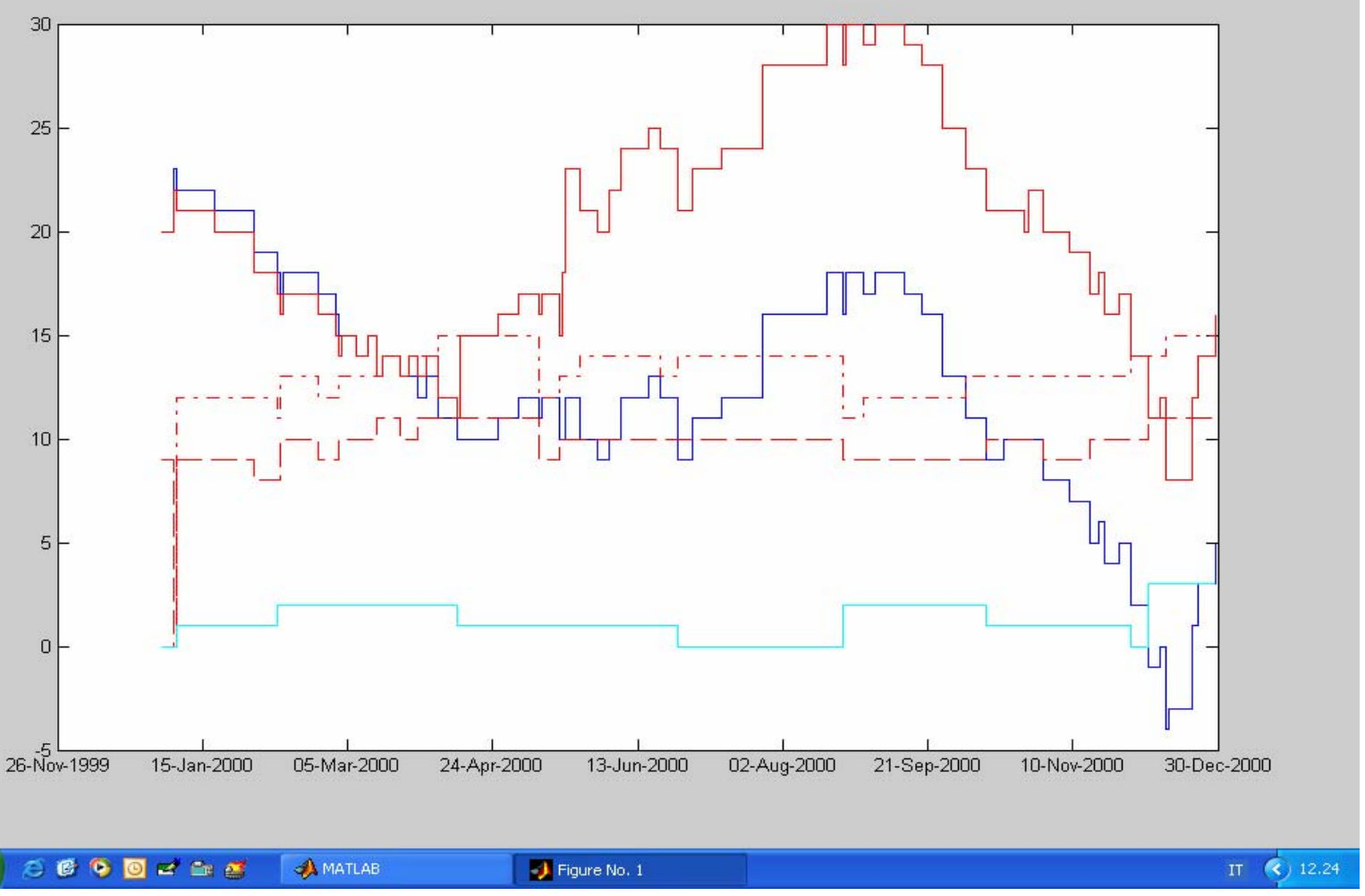

Figure 39: CBN grinding wheel inventory level trend. 


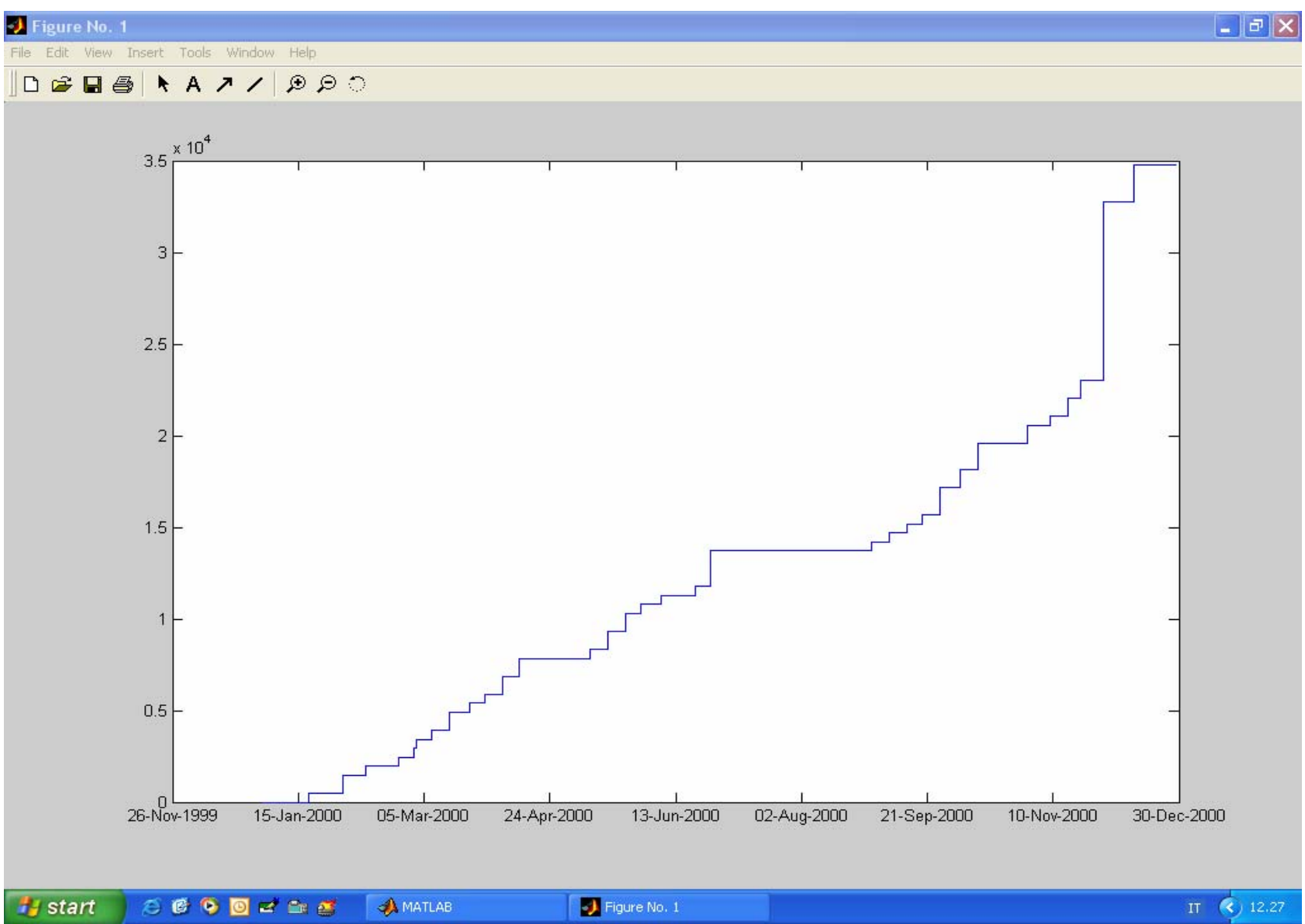

Figure 40: Tool supply cost plot.

\section{- 7 Figure No. 1}

File Edit View Insert Tools Window Help

吅司回|A

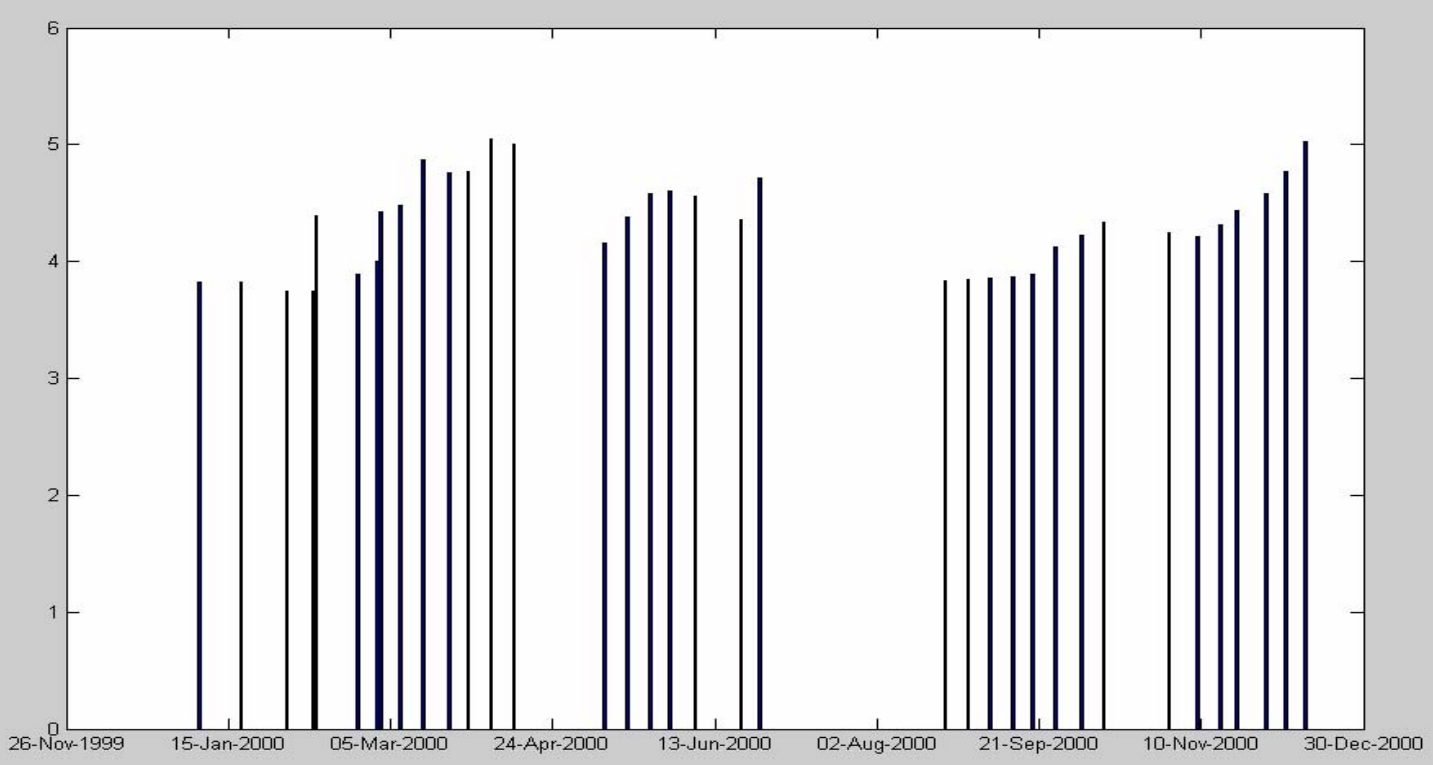


The software also visualizes the diagram related to the "tool supply cost" in the Figure 39.

Moreover, the software visualizes the diagram related to the "adaptive tool demand rate" in the Figure 40.

Before starting a new simulation, we must save the workspace as a file ".mat". The name of this file is constituted by the part-number with the extension ".mat". In our example the name of the file is "U5103N.mat".

\section{SIMULATION RESULTS}

Table 1 summarises the list of P/Ns simulated through the different FTMS paradigms. The simulation results are reported in Appendix for each FTMS paradigm.

\begin{tabular}{|c|c|c|c|}
\hline P/N & INVADAPT & I-FUTURE & INVADAPT_NS \\
\hline M8137161 & & $\mathbf{X}$ & \\
\hline M8110855 & & $\mathbf{X}$ & \\
\hline M8117351 & & $\mathbf{X}$ & \\
\hline M3942461 & & & $\mathbf{X}$ \\
\hline M8125281 & $\mathbf{X}$ & $\mathbf{X}$ & $\mathbf{X}$ \\
\hline M8136216 & $\mathbf{X}$ & $\mathbf{X}$ & $\mathbf{X}$ \\
\hline M8136217 & & $\mathbf{X}$ & $\mathbf{X}$ \\
\hline M8136219 & & $\mathbf{X}$ & $\mathbf{X}$ \\
\hline U5101N & $\mathbf{X}$ & $\mathbf{X}$ & $\mathbf{X}$ \\
\hline U5103N & $\mathbf{X}$ & $\mathbf{X}$ & $\mathbf{X}$ \\
\hline U5105 & $\mathbf{X}$ & $\mathbf{X}$ & $\mathbf{X}$ \\
\hline U6115 & $\mathbf{X}$ & $\mathbf{X}$ & $\mathbf{X}$ \\
\hline M3916091 & & & $\mathbf{X}$ \\
\hline M8114268 & & $\mathbf{X}$ & $\mathbf{X}$ \\
\hline M8124015 & & & $\mathbf{X}$ \\
\hline M8125164 & & $\mathbf{X}$ & $\mathbf{X}$ \\
\hline U5100N & $\mathbf{X}$ & & $\mathbf{X}$ \\
\hline M8125177 & $\mathbf{X}$ & $\mathbf{X}$ & $\mathbf{X}$ \\
\hline M3941142-1 & $\mathbf{X}$ & & \\
\hline U5102N & $\mathbf{X}$ & & \\
\hline U8102 & $\mathbf{X}$ & & \\
\hline M3916103 & $\mathbf{X}$ & & \\
\hline M3942462 & $\mathbf{X}$ & & \\
\hline M3941142-2 & $\mathbf{X}$ & & \\
\hline M3942461 & $\mathbf{X}$ & & \\
\hline & & & \\
\hline
\end{tabular}

Table 1: Summary of P/Ns simulated through the diverse FTMS paradigms.

\subsection{Simulation results through INVADAPT}

In Appendix A, the results obtained through the INVADAPT simulation are presented.

For each simulation, three plots are reported in the corresponding figure.

The first plot reports the historical and simulated on-hand inventory level trend, in one year. Time (month/year) is reported on the horizontal axis while the inventory level is reported on the vertical axis, On the same plot, also the tool supply cost, the historical tool cost, the cost variation (in percentage), and the values of $I_{\min }$ and $I_{\max }$ (two control range limits for the inventory level) are reported.

The second plot reports the adaptive tool demand rate. On the horizontal axis the wear out event dates are reported; on the vertical one, the tool demand rate (units/month) is reported.

The third plot reports the tool supply cost. On the horizontal axis the event data are reported, on the vertical one, the cost is reported.

At the bottom of the figure, the final simulation report is summarized, including:

- The number of worn-out grinding wheels on-hold

- The number of dressed grinding wheels

- The number of purchased grinding wheels

- The number of undelivered new grinding wheels

- The tool supply cost

- The historical tool cost

- $\quad$ The tool supply percentage

The part-numbers simulated through INVADAPT were:

- M3941142-1 (Figure 42)

- M3941142-2 (Figure 55)

- $\quad$ M3916103 (Figure 49)

- M3942462 (Figure 43)

- $\quad$ M8125177 (Figure 51)

- M8125281 (Figure 44)

- M8136216 (Figure 52)

- $\quad$ U5101N (Figure 45)

- U5103N (Figure 53)

- U5105 (Figure 46)

- U6115 (Figure 54)

- $\quad$ U8102 (Figure 47)

- M3942461 (Figure 50)

- U5100 (Figure 48)

- U5102N (Figure 56)

\subsection{Simulation results through I-FUTURE}

In Appendix B, the results obtained through the I_FUTURE simulation are presented.

For each simulation, two plots are report in figure.

The first plot reports the historical and simulated on-hand inventory level trend, in one year. Time (month/year) is reported on the horizontal axis while the inventory level is reported on the vertical axis, On the same plot, also the tool supply cost, the historical tool cost, the cost variation (in percentage), and the values of $I_{\min }$ and $I_{\max }$ (two control range limits for the inventory level) are reported.

The second plot reports the adaptive tool demand rate. On the horizontal axis the worn-out serial-number are reported; on the vertical one, the tool demand rate (units/month) is reported.

At the bottom of the figure, the final simulation report is summarized, including:

- The number of worn-out grinding wheels on-hold

- The number of dressed grinding wheels

- The number of purchased grinding wheels

- The number of undelivered new grinding wheels

- The tool supply cost

- The historical tool cost

- The tool supply percentage

The part-numbers simulated through I-FUTURE are:

$\begin{array}{ll}- & M 8137161 \text { (Figure 57) } \\ - & \text { M8110855 (Figure 59) } \\ - & \text { M8117351 (Figure 58) } \\ - & \text { M8125164 (Figure 69) } \\ - & \text { M8125177(Figure 68) } \\ - & \text { M8125281(Figure 67) } \\ - & \text { M8136216 (Figure 66) } \\ - & \text { M8136217(Figure 65) } \\ - & \text { M8136219 (Figure 64) }\end{array}$


- $\quad$ U5101N (Figure 63)

- U5103N (Figure 62)

- U5105 (Figure 61)

- U6115(Figure 60)

- M8114268 (Figure 70)

\subsection{Simulation results through INVADAPT NS}

In Appendix $\mathrm{C}$, the results obtained through the INVADAPT_NS simulation are presented.

For each simulation, three plots are report in figure:

- The first plot reports the historical and simulated on-hand inventory level trend, in one year. Time (month/year) is reported on the horizontal axis while the inventory level is reported on the vertical axis, On the same plot, also the tool supply cost, the historical tool cost, the cost variation (in percentage), and the values of $I_{\min }$ and $I_{\max }$ (two control range limits for the inventory level) are reported.

- The second plot reports the adaptive tool demand rate. On the horizontal axis the wear out event dates are reported; on the vertical one, the tool demand rate (units/month) is reported.

- The third plot ireports the tool supply cost. On the horizontal axis the event data are reported, on the vertical one, the cost is reported

At the bottom of the figure, the final simulation report is summarized, including:

- The number of worn-out grinding wheels on-hold

- The number of dressed grinding wheels

- The number of purchased grinding wheels

- The number of undelivered new grinding wheels

- The tool supply cost

- The historical tool cost

- The tool supply percentage

The P/Ns simulated through INVADAPT_NS were:

- $\quad$ M3916091 (Figure 71)

- M8114268 (Figure 73)

- M8124015 (Figure 74)

- M8136219 (Figure 80)

- U5103N (Figure 83)

- U5105 (Figure 84)

- U6115 (Figure85)

- M3942461 (Figure 72)

- M8125177 (Figure 76)

- M8125281 (Figure 77)

- M8136216 (Figure 78)

- M8136217 (Figure79)

- U5101N (Figure 82)

- U5100N (Figure 81)

- M8125164 (Figure 75)

\section{CONCLUSIONS AND FUTURE WORK}

In this work, tool inventory management simulations were carried out using diverse Flexible Tool Management Strategy (FTMS) paradigms integrated in a Multi-Agent Tool Management System (MATMS) for automatic tool procurement, and the obtained results were compared with reference to real industrial cases.

As regards future work, a comprehensive evaluation of the pros, cons and capabilities of the diverse FTMS approaches will be performed in view of the trade-off typical of the inventory sizing dilemma between tool supply cost saving and tool stock out risk minimisation.

\section{REFERENCES}

[1] Fox, M.S., Barbuceanu, M., Teigen, R., 2000, Agent-Oriented Supply-Chain Management, Int. J. of Flexible Manufacturing Systems, 12: 165-188.

[2] Yuan, Y., Liang, T.P., Zhang, J.J., 2001, Using Agent Technology to Support Supply Chain Management: Potentials and Challenges, M. G. De Groote School of Business, Working Paper N. 453.

[3] Sycara, K.P., 1998, Multi-Agent Systems, Al Magazine, Summer 1998: 79-92.

[4] Teti, R., D'Addona, D., 2003, Agent-Based Multiple Supplier Tool Management System, $36^{\text {th }}$ CIRP Int. Sem. on Manufacturing Systems - ISMS 2003, Saarbrücken, 3-5 June: 39-45.

[5] Teti, R., D'Addona, D., 2003, Grinding Wheel Management through Neuro-Fuzzy Forecasting of Dressing Time, Annals of CIRP, 52/1: 407-410.

[6] Teti, R., D'Addona, D., 2003, Multiple Supplier Neuro-Fuzzy Reliable Delivery Forecasting for Tool Management in a Supply Network, $6^{\text {th }}$ AITEM Conf., Gaeta, 8-10 September.

[7] Van Hentenryck, 1999, The OPL Optimisation Programming Language, Massachusetts Institute of Technology, Boston, USA.

[8] Teti, R., D'Addona, D., 2004, Adaptive NF Tool Delivery Forecasting for Flexible Tool Management in a Supply Network, $5^{\text {th }}$ Int. Workshop on Emergent Synthesis - IWES '04, Budapest, 24-25 May.

[9] Jang, J.-S. R., 1993, ANFIS: Adaptive-NetworkBased Fuzzy Inference System, IEEE Trans. on Systems, Man, and Cybernetics, 23/3: 665-685.

[10] Jang, J.-S. R., 1995, Neuro-Fuzzy Modelling and Control, IEEE, 83: 378-405.

[11] Teti, R., D'Addona, D., Segreto, T., 2004, Flexible Tool Management in a Multi-Agent Modelled Supply Network, $37^{\text {th }}$ CIRP Int. Sem. on Mftg. Systems ISMS 2004, Budapest, 19-21 May: 351-356. 